Article

\title{
Gold Nanoparticles as Boron Carriers for Boron Neutron Capture Therapy: Synthesis, Radiolabelling and In Vivo Evaluation
}

\author{
Krishna R. Pulagam ${ }^{1}{ }^{\circledR}$, Kiran B. Gona ${ }^{1,2,3}$, Vanessa Gómez-Vallejo ${ }^{4}$, Jan Meijer ${ }^{5}$, \\ Carolin Zilberfain ${ }^{6}$, Irina Estrela-Lopis ${ }^{6}$, Zuriñe Baz ${ }^{1}$, Unai Cossío ${ }^{7}$ and Jordi Llop ${ }^{1,8, *}$ \\ 1 Radiochemistry and Nuclear Imaging Group, CIC biomaGUNE, 20014 San Sebastian, Spain; \\ krpulagam@cicbiomagune.es (K.R.P.); kirangonas@gmail.com (K.B.G.); zbaz@cicbiomagune.es (Z.B.) \\ 2 Cardiovascular Molecular Imaging Laboratory, Section of Cardiovascular Medicine and Yale Cardiovascular \\ Research Center, Yale University School of Medicine, New Haven, CT 06511, USA \\ 3 Veterans Affairs Connecticut Healthcare System, West Haven, CT 06516, USA \\ 4 Radiochemistry Platform, CIC biomaGUNE, 20014 San Sebastian, Spain; vgomez@cicbiomagune.es \\ 5 Institute of Medical Physics and Biophysics, Leipzig University, Härtelstrasse 16-18, 04107 Leipzig, Germany; \\ jan.meijer@uni-leipzig.de \\ 6 Felix Bloch Institute for Solid State Physics, Leipzig University, Linnéstraße 5, 04103 Leipzig, Germany; \\ Carolin.Merker@medizin.uni-leipzig.de (C.Z.); Irina.Estrela-Lopis@medizin.uni-leipzig.de (I.E.-L.) \\ 7 Radioimaging and Image Analysis Platform, CIC biomaGUNE, 20014 San Sebastian, Spain; \\ ucossio@cicbiomagune.es \\ 8 Centro de Investigación Biomédica en red Enfermedades Respiratorias-CIBERES, 28029 Madrid, Spain \\ * Correspondence: jllop@cicbiomagune.es; Tel.: +34-943-005-333
}

Academic Editor: Piotr Kaszyński

Received: 16 September 2019; Accepted: 1 October 2019; Published: 7 October 2019

\begin{abstract}
Background: Boron Neutron Capture Therapy (BNCT) is a binary approach to cancer therapy that requires accumulation of boron atoms preferentially in tumour cells. This can be achieved by using nanoparticles as boron carriers and taking advantage of the enhanced permeability and retention (EPR) effect. Here, we present the preparation and characterization of size and shape-tuned gold NPs (AuNPs) stabilised with polyethylene glycol (PEG) and functionalized with the boron-rich anion cobalt bis(dicarbollide), commonly known as COSAN. The resulting NPs were radiolabelled with ${ }^{124} \mathrm{I}$ both at the core and the shell, and were evaluated in vivo in a mouse model of human fibrosarcoma (HT1080 cells) using positron emission tomography (PET). Methods: The thiolated COSAN derivatives for subsequent attachment to the gold surface were synthesized by reaction of COSAN with tetrahydropyran (THP) followed by ring opening using potassium thioacetate (KSAc). Iodination on one of the boron atoms of the cluster was also carried out to enable subsequent radiolabelling of the boron cage. AuNPs grafted with mPEG-SH (5 Kda) and thiolated COSAN were prepared by ligand displacement. Radiolabelling was carried out both at the shell (isotopic exchange) and at the core (anionic absorption) of the NPs using ${ }^{124}$ I to enable PET imaging. Results: Stable gold nanoparticles simultaneously functionalised with PEG and COSAN (PEG-AuNPs@[4] $]^{-}$) with hydrodynamic diameter of $37.8 \pm 0.5 \mathrm{~nm}$, core diameter of $19.2 \pm 1.4 \mathrm{~nm}$ and $\xi$-potential of $-18.0 \pm 0.7 \mathrm{mV}$ were obtained. The presence of the COSAN on the surface of the NPs was confirmed by Raman Spectroscopy and UV-Vis spectrophotometry. PEG-AuNPs@[4] $]^{-}$could be efficiently labelled with ${ }^{124}$ I both at the core and the shell. Biodistribution studies in a xenograft mouse model of human fibrosarcoma showed major accumulation in liver, lungs and spleen, and poor accumulation in the tumour. The dual labelling approach confirmed the in vivo stability of the PEG-AuNPs@[4]Conclusions: PEG stabilized, COSAN-functionalised AuNPs could be synthesized, radiolabelled and evaluated in vivo using PET. The low tumour accumulation in the animal model assayed points to the need of tuning the size and geometry of the gold core for future studies.
\end{abstract}


Keywords: boron neutron capture therapy; gold nanoparticles; cobalt bis(dicarbollide); positron emission tomography; radiolabelling; iodine-124; HT1080

\section{Introduction}

Despite recent advances, an estimated 14.1 million new cancer cases and 8.2 million cancer-related deaths occurred in 2012 [1]. The International Agency for Research on Cancer (IARC) predicts a substantive increase to 19.3 million new cancer cases per year by 2025, due to growth and ageing of the global population [1]. Hence, there is an urgent need to develop new diagnostic and therapeutic tools.

Binary approaches to cancer therapy, in which two low-toxicity modalities are co-localised in the tumour to become active, are a promising strategy to improve patient outcomes and decrease side effects. Two examples are photodynamic therapy (PDT) [2,3] and photothermal therapy (PTT) [4,5], which are established techniques in which photosensitising agents are administered, followed by targeted irradiation of the treated area with visible or near-infrared (IR) laser light. However, PDT and PTT are limited by the low penetration of visible and IR light into tissues, which limits their application to superficial skin tumours or those at the surface of internal organs or cavities.

Another binary approach to cancer therapy is Boron Neutron Capture Therapy (BNCT), which is based on the ability of the stable isotope boron-10 $\left({ }^{10} \mathrm{~B}\right)$ to capture thermal neutrons. The interaction of an incident thermal neutron with a ${ }^{10} \mathrm{~B}$ atom results in the ${ }^{10} \mathrm{~B}(\mathrm{n}, \alpha, \gamma){ }^{7} \mathrm{Li}$ nuclear reaction [6]. A Particles and ${ }^{7} \mathrm{Li}$ recoil ions have high linear energy transfer properties and path lengths in the range of the diameter of a single cell. Hence, if cancer cells selectively take up a sufficient amount of ${ }^{10} \mathrm{~B}$ and are irradiated with thermal neutrons (ca. $0.5-10 \mathrm{keV}$ ), the $\alpha$ particles and ${ }^{7} \mathrm{Li}$ ions produced as a consequence of the ${ }^{10} \mathrm{~B}(\mathrm{n}, \alpha, \gamma)^{7} \mathrm{Li}$ nuclear reaction result in cellular damage and trigger cell death, while sparing healthy surrounding tissue.

Over years, abnormal metabolism and the over-expression of membrane receptors have been widely exploited to develop drug candidates capable to accumulate ${ }^{10} \mathrm{~B}$ nuclei in cancer cells. In this context, boronated carbohydrates, amino acids, peptides, nucleic acids and immunoconjugates $[7,8]$ have been proposed as potential BNCT drug candidates. Unfortunately, only two compounds are currently applied in the clinical practice, i.e., sodium borocaptate (BSH) and $p$-boronophenylalanine (BPA) [9], and their application is restricted to a limited number of tumour types [10].

In the recent years, researchers have exploited the enhanced permeability and retention (EPR) effect to achieve passive accumulation of nanosized drugs in a wide range of tumours. This phenomenon has opened new opportunities for the development of drug-enriched nanomedicines with potential application in BNCT. To date, nanocarriers such as liposomes [11-15], carbon [16] and boron nitride nanotubes [17-20], magnetic nanoparticles [21,22], boron carbide nanoparticles [23,24] and borosilicates [25] have been synthesized and eventually investigated as BNCT drugs at the pre-clinical level.

Among all nanomaterials, multifunctional gold nanoparticles (AuNPs), composed of an inorganic metallic gold core surrounded by an organic and/or biomolecular monolayer, have become especially relevant in biomedicine. The core material is chemically inert and non-toxic, both shape and size can be easily tuned and monolayer properties can be modulated due to the well-defined surface chemistry of gold [26]. Consequently, different functionalized gold assemblies have been synthesized and evaluated in different biomedical applications [27-29], including their use as potential boron carriers in the context of BNCT. In one of the first works, Schmid et al. reported on the preparation of gold clusters functionalised with BSH using a phase transfer reaction over 6 weeks [30]. Subsequent works comprise the preparation of polymer-stabilized gold nanoparticles using 0 -carborane functionalised polystyrene [31], the preparation of mercaptocarborane- [32,33], o-carborane- [34,35] and borane-capped AuNPs [36], and the preparation of carborane-capped gold nanoclusters [37]. 
Here, we present the preparation of size and shape-tuned gold NPs functionalized simultaneously with poly(ethylene glycol) methyl ether thiol and the inorganic, boron-based molecule cobalt bis(dicarbollide), [3,3'-Co(1,2- $\left.\left.\mathrm{C}_{2} \mathrm{~B}_{9} \mathrm{H}_{11}\right)_{2}\right]^{-}$, commonly known as COSAN, a stable and water soluble complex in which the cobalt atom is sandwiched between two $\eta^{5}$-bonding $\left[\mathrm{C}_{2} \mathrm{~B}_{9} \mathrm{H}_{11}\right]^{2-}$ moieties $[38,39]$. The resulting functionalized NPs were radiolabelled with ${ }^{124} \mathrm{I}$, a positron emitter with a half-life of 4.17 days, using two different strategies; namely, the radiolabel was incorporated either on the surface of the gold core or covalently attached to the COSAN. Whole body imaging studies using Positron Emission Tomography (PET) were carried out in a mouse cancer model, generated by subcutaneous inoculation of HT1080 (human fibrosarcoma) cells, in order to assess (i) the capability of the multi-functionalized AuNPs to passively accumulate in the tumour; and (ii) the in vivo stability of the NPs and their biological fate.

\section{Results and Discussion}

\subsection{Synthesis of COSAN Derivatives}

As a first step in the development of the novel boron-rich AuNPs, COSAN derivatives bearing a thiol group for subsequent attachment to AuNPs were synthesized following a previously published methodology [40] with minor modifications (Scheme 1). The reaction of $\left[3,3^{\prime}-\mathrm{Co}\left(8-\mathrm{C}_{5} \mathrm{H}_{10} \mathrm{O}-1,2-\mathrm{C}_{2} \mathrm{~B}_{9} \mathrm{H}_{10}\right)\left(1^{\prime}, 2^{\prime}-\mathrm{C}_{2} \mathrm{~B}_{9} \mathrm{H}_{11}\right)\right]$ (2; synthesized as described, [40]) with potassium thioacetate (KSAc) yielded [3] ${ }^{-}$with overall yield of $52 \%$, which led to [4] $]^{-}$in almost quantitative yield after basic hydrolysis. In parallel, COSAN derivatives simultaneously incorporating a thiol group and an iodine atom, the latter to enable radiolabelling with the positron emitter ${ }^{124}$ I before attachment to the AuNPs (shell labelling), was achieved by reaction of [3] ${ }^{-}$with sodium iodide, chloramine-T and acetic acid in acetonitrile overnight at room temperature to yield [5] ${ }^{-}$in $69 \%$ yield after purification. Basic hydrolysis yielded the thio-derivative [6] ${ }^{-}$ready for incorporation into NPs. Characterization using ${ }^{1} \mathrm{H}-,{ }^{11} \mathrm{~B}-$, and ${ }^{13} \mathrm{C}-\mathrm{NMR}$ confirmed the presence of the desired compounds (see experimental section and Supplementary Materials).

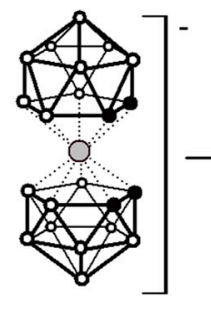

[1]

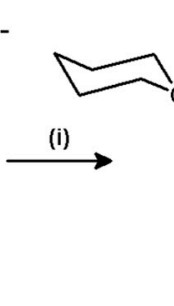

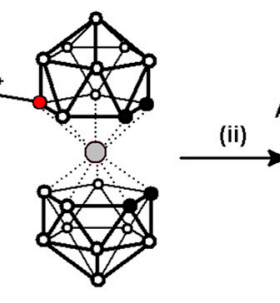

(ii)

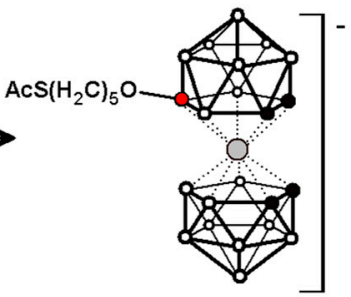

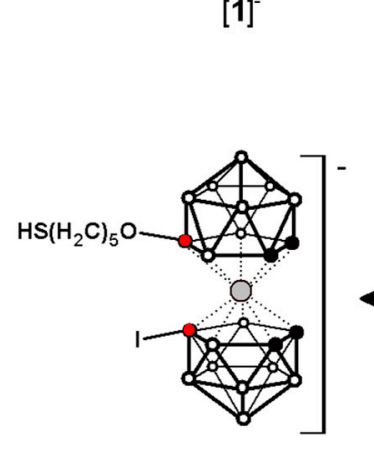

[6]
2
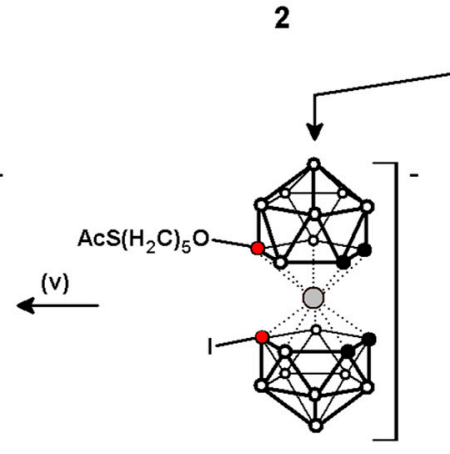

$[5]^{-}$

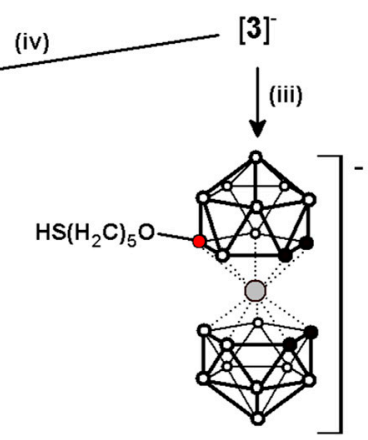

$[4]^{-}$

$$
\text { - B O B-H } \bullet \text { C-H } \bigcirc \mathrm{Co}^{3+}
$$

Scheme 1. Synthesis of functionalized COSAN derivatives 2, $[3]^{-},[4]^{-},[5]^{-}$and $[6]^{-}$. (i) $\mathrm{THP}$, dimethylsulphate, $\mathrm{H}_{2} \mathrm{SO}_{4}$; (ii) $\mathrm{KSAc}$; (iii) $\mathrm{NaOMe}, \mathrm{MeOH}$; (iv) $\mathrm{CH}_{3} \mathrm{CN}, \mathrm{NaI}$, Chloramine-T; (v) $\mathrm{NaOMe}, \mathrm{MeOH}$. 


\subsection{Synthesis of Functionalised AuNPs}

For successful clinical application, a BNCT drug should deposit a concentration of ${ }^{10} \mathrm{~B}$ in the tumour in the range $20-35 \mu \mathrm{g}{ }^{10} \mathrm{~B} / \mathrm{g}$ of tissue, although lower amounts might be sufficient if the boron atoms are internalized into cells [41,42]. Additionally, high tumour-to-normal tissue and tumour-to-blood ratios should be achieved in order to prevent damage to healthy tissue and blood vasculature during neutron irradiation. Achieving these values is highly challenging, and nanotechnology has opened new opportunities due to the well-known EPR effect which results in passive accumulation of nanosized materials in tumour tissue. Here, and based on the previous work reported by Cioran et al. [32] we envisaged the possibility of using gold nanoparticles as boron carriers. Besides the easy functionalization chemistry, gold nanomaterials are chemically inert and non-toxic and both shape and size can be easily tuned [26]. Among all the possibilities, we decided to start with spherical particles with a size within the optimal range to achieve tumour accumulation [43]. In addition to the boron clusters, we decided to incorporate PEG chains on the NP surface in order to enhance the stability of the NPs in biological media and increase circulation time.

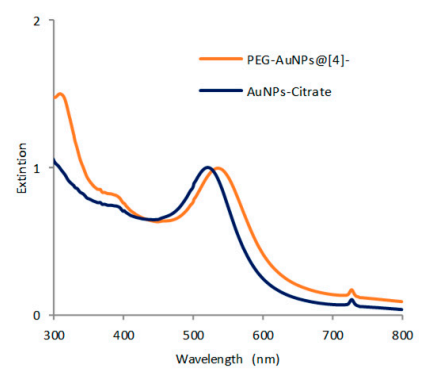

(a)

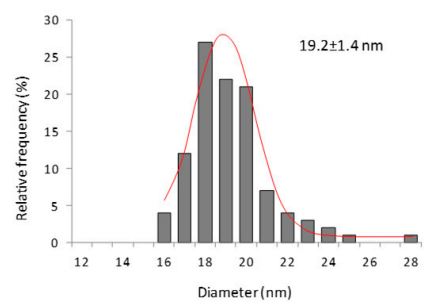

(c)

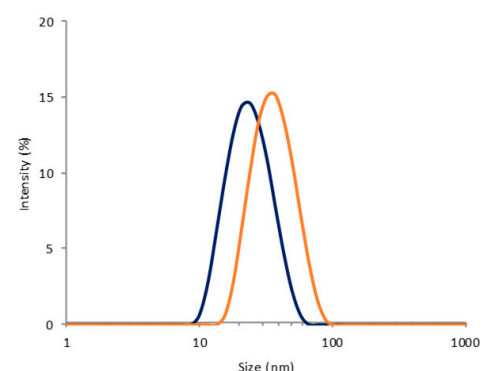

(b)

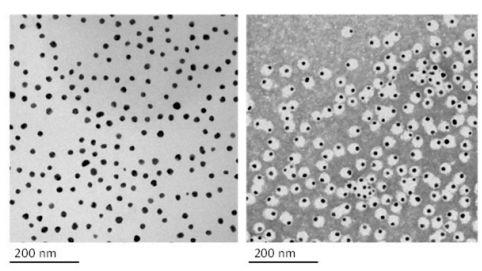

(d)

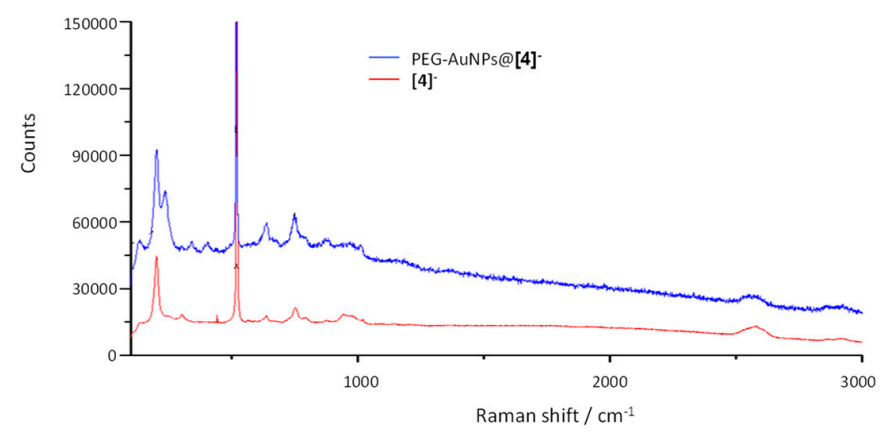

(e)

Figure 1. (a) UV-Vis spectra corresponding to citrate stabilized AuNPs (AuNPs-Citrate, blue, $\lambda_{\max }$ $=524 \mathrm{~nm}$ ) and PEG-stabilized AuNPs@[4] ${ }^{-}$(PEG-AuNPs@[4] $]^{-}$, red, $\lambda_{\max }=531 \mathrm{~nm}$ for the gold plasmon; $\lambda_{\max }=310 \mathrm{~nm}$ corresponds to compound [4] $\left.]^{-}\right) ;(\mathbf{b})$ Size distribution ranges as determined by DLS (volume distribution) for AuNPs-Citrate and PEG-AuNPs@[4] ${ }^{-}$(same colour code as in (a)); (c) Particle size distribution of PEG-AuNPs@[4] $]^{-}$as determined by TEM; (d) representative TEM images of AuNPs-Citrate and PEG-AuNPs@[4] $]^{-}$; (e) Raman spectra for PEG-AuNPs@[4] $]^{-}$and compound $[4]^{-}$. 
COSAN functionalized-PEG stabilized gold NPs (PEG-AuNPs@[4] ${ }^{-}$) were prepared by mixing spherical, citrate-stabilized 18-20 nm gold NPs (AuNPs-citrate, prepared following the Turkevich method [44]) with a mixture of [4] ${ }^{-}$and $5 \mathrm{KDa}$ PEG-thiol in aqueous media. The amount of COSAN in the final PEG-AuNPs@[4] $]^{-}$, determined by ICP-MS was estimated to be ca. $0.09 \mathrm{mg}$ of boron $/ \mathrm{mg}$ of gold. The simultaneous incorporation of COSAN and PEG on the surface of the NPs resulted in a bathochromic shift in the longitudinal surface plasmon resonance (SPR) band from $524 \mathrm{~nm}$ to $531 \mathrm{~nm}$ (Figure 1a). Additionally, another absorption band appeared at ca. $310 \mathrm{~nm}$, close to the maximum absorption of COSAN (314 nm), confirming successful incorporation of the boron cluster on the surface of the AuNPs.

Dynamic light scattering analysis performed on AuNPs-Citrate and PEG-AuNPs@[4]- showed a mono-disperse distribution with average hydrodynamic diameter of $24.4 \pm 0.5 \mathrm{~nm}$ and $37.8 \pm 0.5 \mathrm{~nm}$ respectively (Figure 1b). TEM analysis revealed the presence of spherical AuNPs with average particle size of $19.2 \pm 1.4 \mathrm{~nm}$ (Figure 1c,d). PEG-AuNPs@[4] $]^{-}$had a negative $\xi$-potential of $-18.0 \pm 0.7 \mathrm{mV}$ at neutral $\mathrm{pH}$, as expected after the incorporation of the anionic COSAN complex on the surface, and the Raman spectra showed the presence of absorption bands at $2596-2573 \mathrm{~cm}^{-1}$, corresponding to B-H stretching and confirming the presence of the sandwich complex on the NP surface (Figure 1e). Furthermore, X-ray photoelectron spectroscopy (XPS) analysis of PEG-AuNPs@[4] $]^{-}$showed a peak at $780.2 \mathrm{eV}$ in the $\mathrm{Co} 2 \mathrm{p}$ spectrum, corresponding to Co-B bonds; peaks at 192.8 and $188.5 \mathrm{eV}$, corresponding to B-O and C-B bonds in the B 1 s spectrum; peaks at 87.5 and $83.5 \mathrm{eV}$, corresponding to Au $4 \mathrm{f} 5 / 2$ and $4 \mathrm{f} 7 / 2$ respectively; and a peak at $162.5 \mathrm{eV}$ in the $\mathrm{S} 2 \mathrm{p}$ spectrum, corresponding to $2 \mathrm{p} 3 / 2 \mathrm{Au}-\mathrm{S}-\mathrm{C}$ bond (Figure 2) [45]. These results confirmed the presence of both cobalt and boron on the surface of AuNPs; furthermore, the NPs have a significant boron load and appropriate size for eventual tumour accumulation.
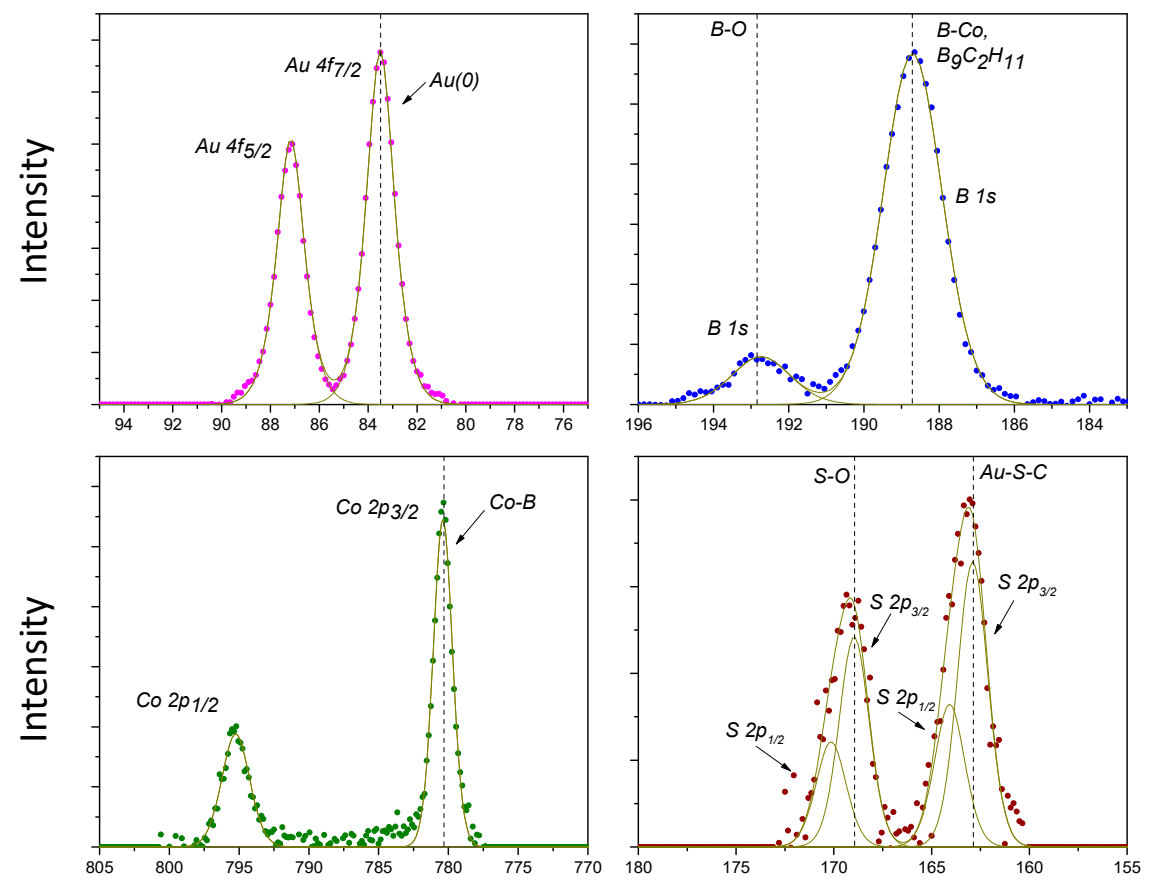

Binding Energy (eV)

Figure 2. XPS spectra of PEG-AuNPs@[4]-.

\subsection{Radiolabelling of AuNPs}

One of the main challenges in BNCT is the determination of the biodistribution of the boron carrier after administration, in order to establish the optimal time window for neutron irradiation. This drawback is even more evident when nanosystems are used as boron carriers, as the determination 
of the biodistribution and fate of NPs after administration into living systems is extremely challenging. One alternative to overcome this drawback consists of incorporating a positron or gamma emitter into the nanoparticle in order to track the location in a time-resolved fashion using PET or Single Photon Emission Computerised Tomography (SPECT) imaging. This approach has been widely reported in the literature in NPs with very different nature [46-52]. Additionally, incorporation of the label both at the core and at the shell of NPs can provide very relevant information about the in vivo stability of the NPs [53].

Here, the decided to tackle the radiolabelling of PEG-AuNPs@[4]- by using two previously reported approaches, in order to incorporate the positron emitter ${ }^{124} \mathrm{I}$ (half-life of 4.2 days) either at the shell or at the core of the NPs (Figure 3).
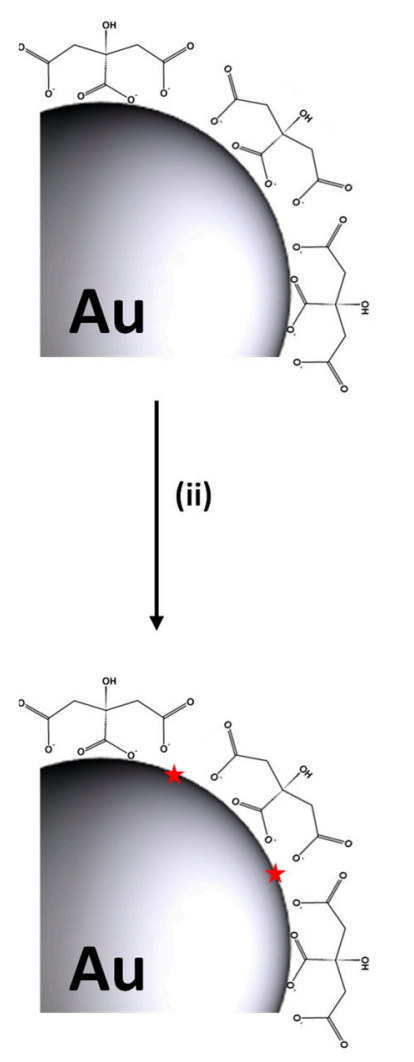

(i)

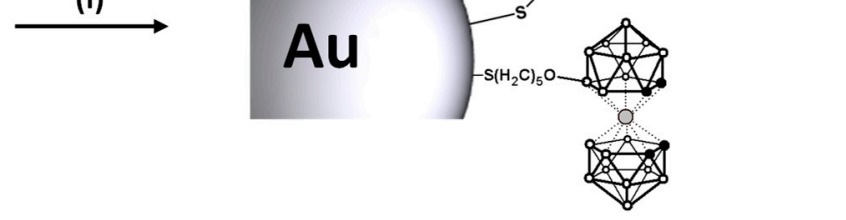

(iii)

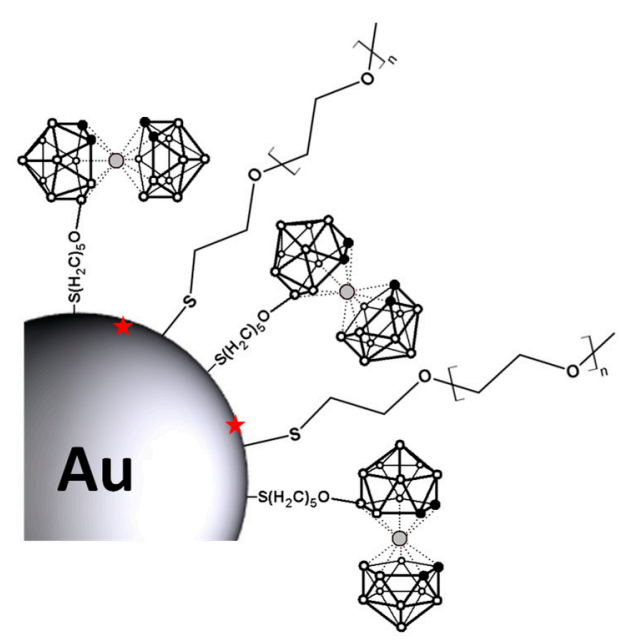

Figure 3. Schematic representation of the different routes followed for the preparation of radiolabelled PEG-AuNPs@[4] $]^{-}$. (i) PEG-SH (5 Kda), ${ }^{124} \mathrm{I}-[6]^{-}+[4]^{-}$; (ii) [ $\left.{ }^{124} \mathrm{I}\right] \mathrm{NaI}$; (iii) PEG-SH (5 Kda), [4] $]^{-}$. The red star stands for the radiolabel $\left({ }^{124} \mathrm{I}\right)$.

In the first approach ${ }^{124} \mathrm{I}-[6]^{-}$was prepared by isotopic exchange, following a methodology previously described in our group [54]. Incorporation ratios of the radiolabel of $69 \pm 6 \%$ were achieved when the reaction was conducted at $100{ }^{\circ} \mathrm{C}$ for $5 \mathrm{~min}$, as determined by HPLC using radiometric detection. These values are in good agreement with those previously described [54]. Purification by semi-preparative HPLC resulted in a solution of chemically and radiochemically pure compound ${ }^{124} \mathrm{I}-[5]^{-}$with radiochemical yield (non-decay corrected) of ca. $60 \%$. Hydrolysis to achieve ${ }^{124} \mathrm{I}-[6]^{-}$was finally carried out before approaching the preparation of radiolabelled NPs and the resulting compound was used without further purification. Subsequent preparation of functionalized, radiolabelled AuNPs 
was carried out following the same process described above, but compound [4] ${ }^{-}$was spiked with ${ }^{124} \mathrm{I}-[6]^{-}$. Radiolabelling efficiency, calculated as the amount of radioactivity present in the NPs related to the starting amount of ${ }^{124} \mathrm{I}-[6]^{-}$was $55 \%$, suggesting that compounds $[4]^{-}$and ${ }^{124} \mathrm{I}_{-}[6]^{-}$are similarly attached to the surface of AuNPs. Analysis of the resulting NPs after complete decay using DLS and TEM showed equivalent properties to those obtained for the non-labelled NPs (results not shown).

The second approach for the preparation of radiolabelled AuNPs was based on the absorption of radioiodine on the surface of the gold core $[55,56]$. Low incorporation efficiencies $(<10 \%)$ were achieved when functionalized NPs were incubated with the radionuclide. These results are not in agreement with previously reported works, in which almost quantitative labelling yields were obtained $[55,56]$. However, incubation of citrate-stabilized NPs with radioiodine resulted in incorporation ratios $>95 \%$ in short times $(10 \mathrm{~min})$, results that are more in line with those previously reported in the literature. Hence, the presence of the COSAN anions on the surface of the NPs seems to hamper the absorption of radioiodide on the surface, probably due to electrostatic repulsion. In view of these results, we decided to incorporate the radiolabel on citrate-stabilized NPs and incorporate both the PEG and COSAN derivatives in a second step (Figure 3).

One of the main limitations of this second labelling approach is the risk of detachment of the absorbed radionuclide. In order to evaluate the radiochemical stability of core-labelled $\left.{ }^{124} \mathrm{I}\right] \mathrm{PEG}-A u N P s @[4]^{-}$, these were incubated in different media, including water, saline, PBS (10 mM), DMEM (cell culture media), mouse plasma and potassium iodide $(10 \mu \mathrm{M})$. After incubation at $37^{\circ} \mathrm{C}$ for $24 \mathrm{~h}$, the NPs were separated from the media by centrifugal filtration and washed three times, and the radiochemical stability was determined as the ratio between the amount of radioactivity in the NPs and the total amount of radioactivity (NPs + media + washings). Good radiochemical stability (>90\%) was observed in all media except potassium iodide (Figure 4), thus confirming the chemisorption of ${ }^{124}$ I and the suitability of the labeling strategy for in vivo studies.

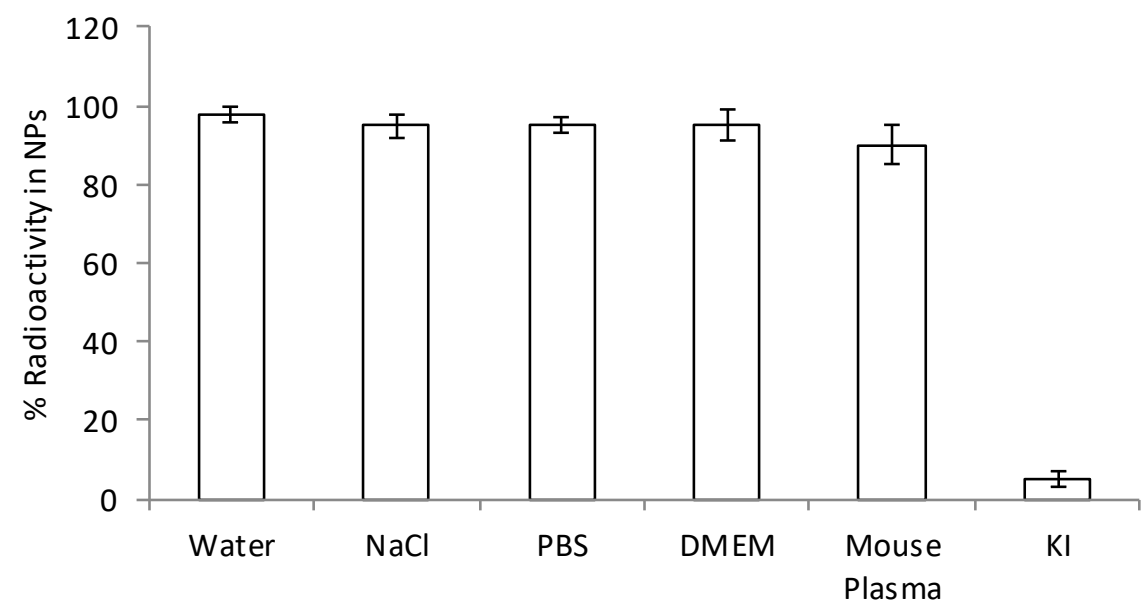

Figure 4. Radiochemical stability of core-labelled PEG-AuNPs@[4] ${ }^{-}$in different media; NaCl: physiologic saline solution (0.9\%); PBS: $10 \mathrm{mM}$ phosphate buffered solution; DMEM: Culture media, cocktail of 8 salts, 15 amino acids, 8 vitamins and glucose; KI: potassium iodide solution $(10 \mu \mathrm{M})$.

Noteworthy, the structural (size and aspect) and chemical properties (composition in terms of boron load) remained unaltered after incorporation of the radiolabel either at the core or at the shell, confirming the suitability of both labelling methods to tackle in vivo experiments.

\subsection{In Vivo Imaging Studies}

The capacity of the newly developed AuNPs ([124I]PEG-AuNPs@[4] $\left.]^{-}\right)$to accumulate in tumour tissue was investigated in a subcutaneous mouse model generated by inoculation of HT1080 cells in nude mice. Traditionally, BNCT has been investigated mainly for brain (gliomas) and head \& neck cancers [57]. However, this therapeutic approach can in principle be evaluated in any cancer type, and 
those cancers with high mortality or lack of efficient therapeutic alternatives are worth to be assayed. Hence, we decided to investigate human fibrosarcoma, which is rare but highly aggressive, and unlike other cancers, metastasizes at early stages. The standard therapy, which includes surgical resection and adjuvant chemotherapy, is ineffective due to local recurrence and distant metastasis [58].

Imaging studies performed in mice enabled the determination of the biodistribution pattern of the labelled particles. Additionally, the inclusion of the label in the two different positions (the core and the shell) was used to gain information about the stability of the core-shell structure, an issue that is rarely tackled in preclinical in vivo investigations. With that aim, animals were injected with the labelled particles and images were acquired immediately after administration (total acquisition time of $60 \mathrm{~min}$ ). Additionally, $30 \mathrm{~min}$ static acquisitions were recorded also at t = 10, 24, 72 and $144 \mathrm{~h}$ post-administration (Figure 4).

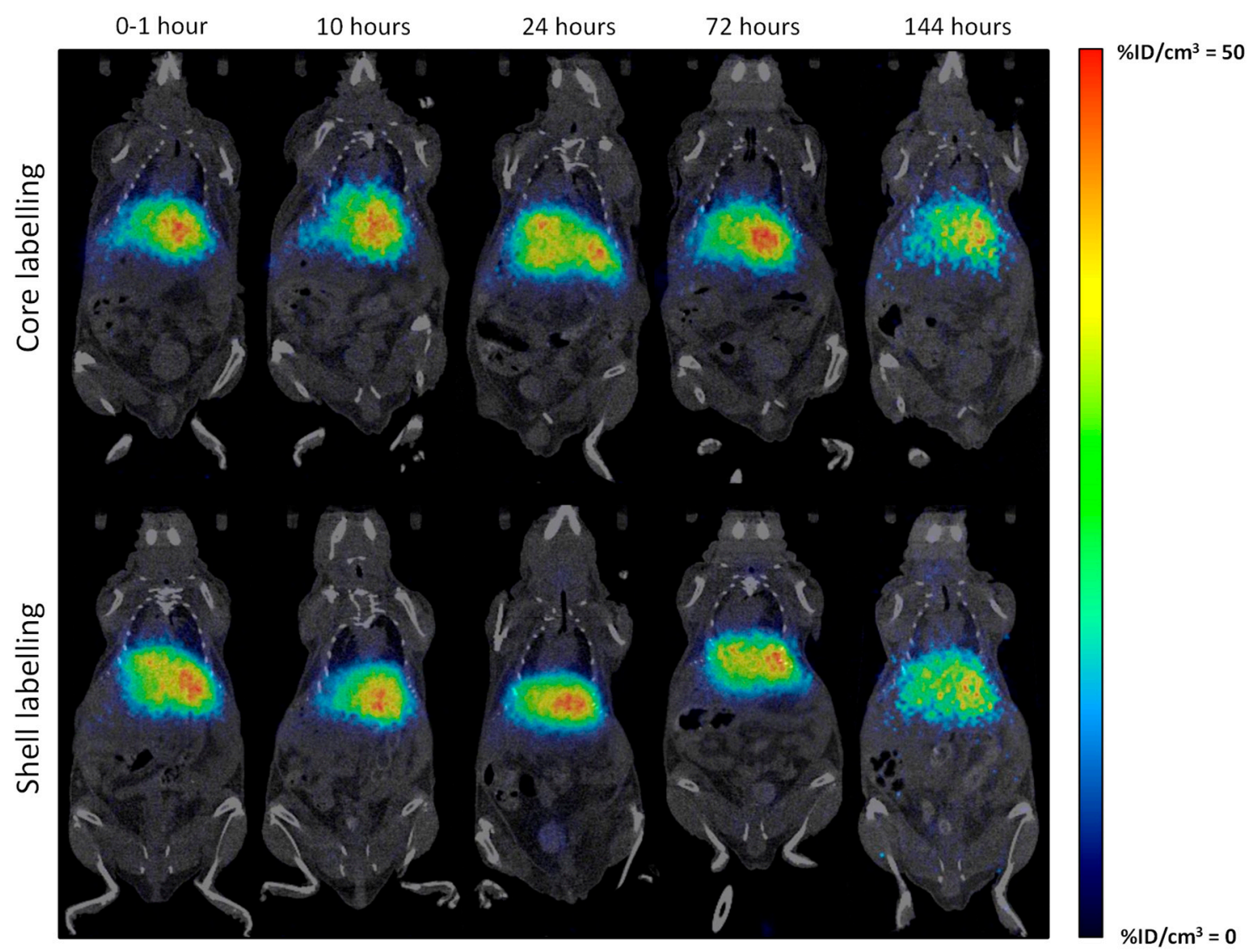

Figure 5. PET images (coronal projections) obtained at different time points after intravenous administration of [124 I]PEG-AuNPs@[4] ${ }^{-}$labelled at the core (top) and at the shell (bottom). PET images have been coregistered with representative CT slices for localization of the radioactive signal. The image labelled as " $0-1 \mathrm{~h}$ " corresponds to the image obtained immediately after administration of the labelled NPs (imaging time $=1 \mathrm{~h}$ ). Values expressed as $\% \mathrm{ID} / \mathrm{cm}^{3}$.

Visual inspection of the images (Figure 5) showed a similar biodistribution pattern for both PEG-AuNPs@[4] $]^{-}$, irrespectively of the position of the label, with high accumulation in the liver already at short times after administration ( $0-1 \mathrm{~h})$. Interestingly, no accumulation was detected in the thyroid gland, confirming the lack of de-iodination during in vivo experimentation. Delineation of volumes of interest (VOIs) in major organs (lungs, liver, bladder, stomach, kidneys, spleen, tumour, heart and thyroid gland) and determination of the uptake as $\%$ of injected dose per $\mathrm{cm}^{3}$ tissue $\left(\% \mathrm{ID} / \mathrm{cm}^{3}\right.$, see Figure 6) revealed similar profiles for both NPs, this confirming the in vivo stability of the core-shell structure. Major accumulation at short times after administration was observed in the liver. For this organ, values at the first time point were $42.2 \pm 4.8$ and $39.1 \pm 5.8 \% \mathrm{ID} / \mathrm{cm}^{3}$ for core and shell labelling, 
respectively. These values progressively decrease with time to reach values close to $10 \%$ ID $/ \mathrm{cm}^{3}$ at $\mathrm{t}=144 \mathrm{~h}$, confirming the progressive elimination of the NPs. Accumulation in the stomach peaked at $\mathrm{t}=24 \mathrm{~h}$ after administration, with progressive elimination from this organ at later time points. Accumulation in the lungs was also significant. Of note, the detection of radioactivity in the heart reflects the presence of labelled NPs in the bloodstream, even at long times after administration. The presence of radioactivity in the bladder at long times after administration confirms slow elimination via urine. This result, together with the detection of radioactive signal in the thyroid gland, suggests the progressive (although very slow) detachment of the radiolabel in both cases (core and shell labelling). Accumulation in the thyroid gland seems to occur faster for core-labelled particles, although these values are subjected to a significant error due to difficulties in delineation of the VOIs, and hence these values should be only considered qualitatively.
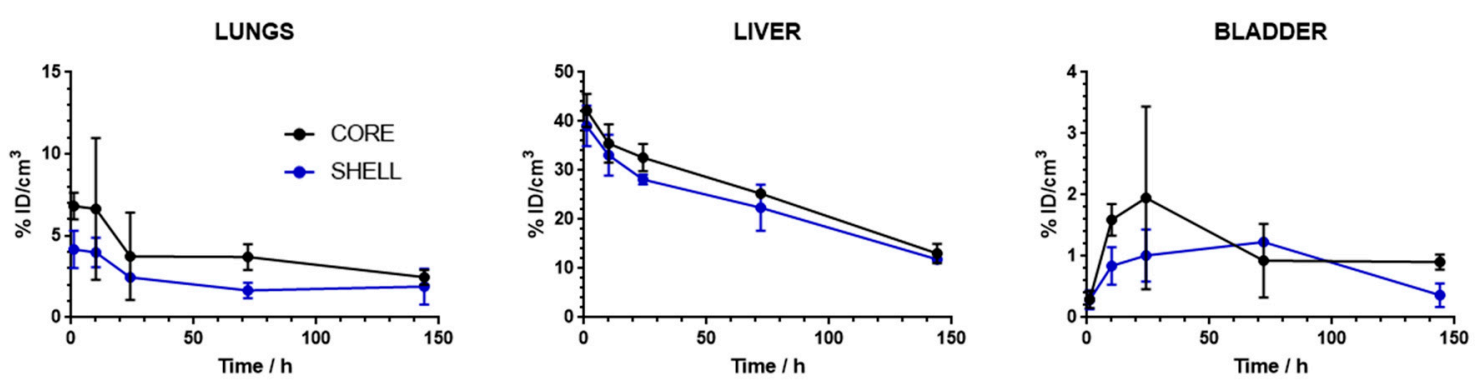

STOMACH

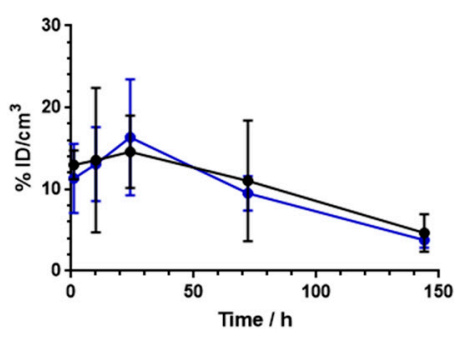

KIDNEYS

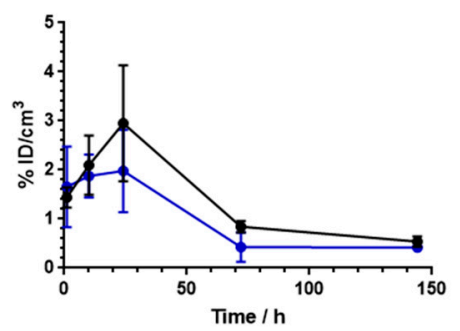

SPLEEN

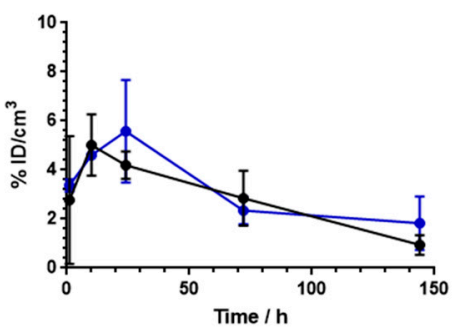

TUMOUR
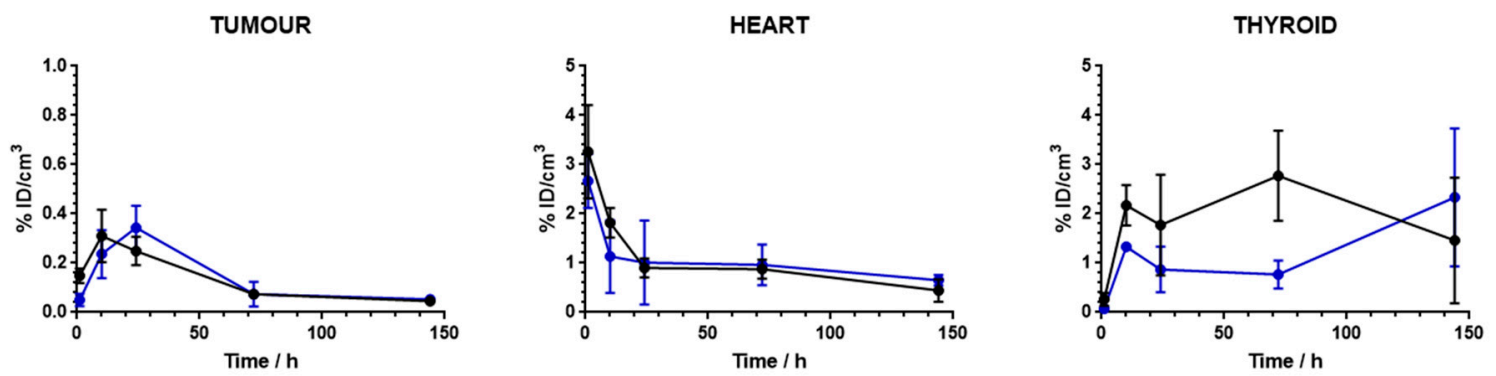

Figure 6. Concentration of radioactivity in the different organs as determined from PET images using the two radiolabelling approaches. Values are expressed as $\% \mathrm{ID} / \mathrm{cm}^{3}$. Values correspond to mean \pm standard deviation, $\mathrm{n}=2$ per labelling strategy and time point.

The accumulation of NPs in the liver observed in vivo was confirmed by ex vivo analysis. With that aim, animals were sacrificed after the last imaging session and the liver was investigated using ion beam microscopy (IBM) and confocal Raman microspectroscopy (CRM) (Figure 7). These label-free techniques have proven efficient for simultaneous quantification and visualization of different NPs in biological environments [59-66], both in vitro and in vivo. The $\mu$ PIXE spectrum extracted from the region of interest (ROI) in Figure $7 \mathrm{~b}$ reveals $X$-ray emission of intrinsic tissues elements, i.e., $P$, S, Ca etc., as well as of gold. Characteristic $\mathrm{L} \alpha, \mathrm{L} \beta$ and $\mathrm{L} \gamma \mathrm{X}$-ray lines of gold at 9.7 keV, $11.4 \mathrm{keV}$ and $13.4 \mathrm{keV}$ were detected in the ROIs shown as green regions in Figure 7a. The structure of several connected hepatic lobules could be identified due to $\mathrm{P}$ and $\mathrm{S}$ distribution in the PIXE images. PIXE 
maps of Au distribution showed a rather homogenous distribution all over those lobules. However, a high resolution image with a size of $100 \times 100 \mu \mathrm{m}$ revealed small gold clusters in the hepatocytes (white circles in Figure 7a).

CRM imaging was additionally used to visualize the distribution pattern of NPs in the liver at subcellular level (Figure 7c). Au NPs were localized in hepatic lobules by using photoluminescence signals of Au. Cytoplasm, nuclei and collagen were visualized on the basis of Raman fingerprint regions of biomolecules [67-69], which are predominantly present in the corresponding constituents of cell. As it can be seen, lobules are surrounded by supporting connective tissue, which was identified in CRM imaging by the presence of collagen. Au NPs were found in the cytoplasm of hepatocytes as well as in close vicinity to their nuclei. Some Au NP aggregates were also detected between adjacent lobules showing a co-localization with the connective tissue.

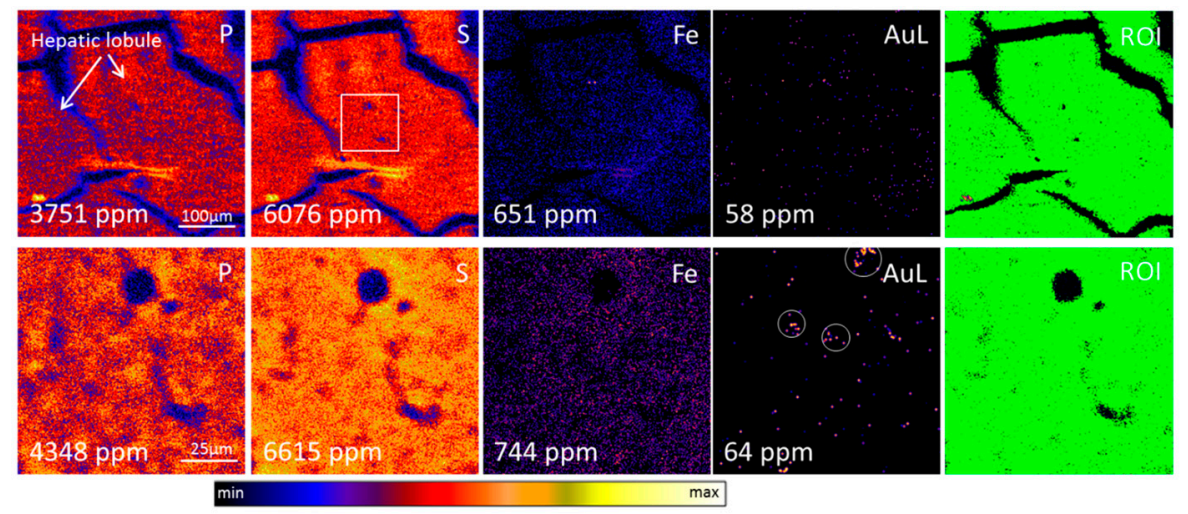

(a)

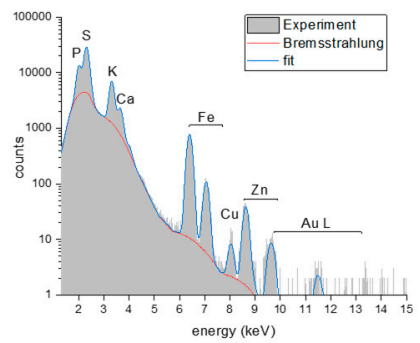

(b)

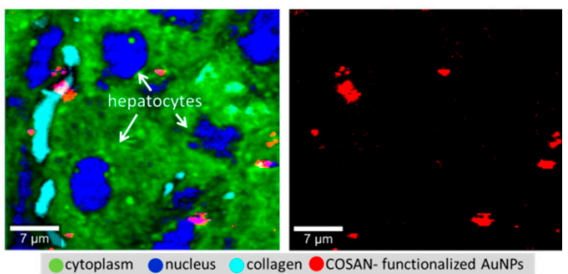

(c)

Figure 7. (a) $\mu \mathrm{PIXE}$ images of intrinsic tissue elements ( $\mathrm{P}, \mathrm{S}, \mathrm{Fe})$ as well as $\mathrm{Au}$ in mouse liver at $\mathrm{t}=72 \mathrm{~h}$ after intravenous administration of $\left[{ }^{124} \mathrm{I}\right] \mathrm{PEG}-\mathrm{AuNPs} @[4]^{-}$. The area in the white rectangle was subsequently scanned with higher resolution. The concentration of elements was calculated from ROIs shown in green on the right side. White arrows denote hepatic lobules. White circles show small gold clusters; (b) PIXE spectrum extracted from ROIs; (c) CRM images of hepatocytes and distribution of [ $\left.{ }^{124} \mathrm{I}\right]$ PEG-AuNPs@[4] $]^{-}$in in mouse liver at $\mathrm{t}=72 \mathrm{~h}$ after intravenous administration of [ $\left.{ }^{124} \mathrm{I}\right]$ PEG-AuNPs@[4] $]^{-}$. The color-coded image (left) shows the overlapping of nucleus, cytoplasm, collagen and COSAN- functionalized Au NPs.

In general terms, our biodistribution data correlates well with previous results obtained with negatively charged NPs. In general, it has been found that, upon single administration, spherical AuNPs localize in liver, kidneys, spleen and lungs, with this phenomenon being size- and shape-dependent. For NPs in our size range, major accumulation should be expected in liver, spleen and lungs [70].

Unfortunately, and in spite of the long circulation time of a fraction of the NPs, our NPs did not show significant accumulation in the tumour, with maximum values below $0.5 \%$ ID $/ \mathrm{cm}^{3}$ irrespective of the labelling approach achieved at $12 \mathrm{~h}$ (core labelling) and $24 \mathrm{~h}$ (shell labelling) after 
administration. Such accumulation progressively decreased with time and is almost undetectable at $t>72 \mathrm{~h}$. The decrease in the amount of radioactivity observed in the tumour could be a consequence of the AuNPs extravasating the tumour again due to high tumour pressure, although internalisation of the NPs in the tumour cells followed by degradation and free iodine release seems a more plausible hypothesis, and explains the accumulation of radioactivity observed in thyroid gland and urine.

Considering that the boron load of our NPs is ca. $9 \%$ and that the administered dose of NPs was $150 \mu \mathrm{g}$ (ca. $7.5 \mathrm{mg} \mathrm{NP} / \mathrm{kg}$ body weight; $0.675 \mathrm{mg} \mathrm{B} / \mathrm{kg}$ body weight), the boron accumulation in the tumour is close to $0.06 \mu \mathrm{g} \mathrm{B} / \mathrm{g}$ of tumour. This value is by far too low to plan any therapeutic experiment and it is inferior to those reported in the literature using other nanocarriers.

The most similar boron carriers described in the literature have been recently reported by Wu et al. [36]. In this work, the authors prepared targeted (functionalised with an anti-HER2 antibody; particle size $54.48 \pm 14.72 \mathrm{~nm}$, as determined by DLS) and non-targeted ( $57.59 \pm 13.90 \mathrm{~nm}$, as determined by DLS) carborane-substituted AuNPs using commercially available citrated-capped AuNPs which were subjected to PEGylation, azide addition, and boron-cage modification on the surface. The resulting AuNPs were radiolabelled with ${ }^{123} \mathrm{I}$, a gamma emitter with a half-life of $13.22 \mathrm{~h}$ which enables in vivo imaging using single photon emission computerised tomography (SPECT). As in our results, high accumulation was found in the liver. However, both targeted and non-targeted AuNPs reported in this previous work showed significant tumor accumulation in a mouse model of gastric cancer over-expressing HER-2. According to in vivo data, accumulation in the tumor was $48.32 \pm 3.11 \% \mathrm{ID} / \mathrm{mL}$ and $7.43 \pm 0.28 \% \mathrm{ID} / \mathrm{mL}$ for the targeted and non-targeted AuNPs, respectively, at $12 \mathrm{~h}$ post injection, with tumor-to-muscle $(\mathrm{T} / \mathrm{M})$ ratios of $12.02 \pm 0.94$ and $1.91 \pm 0.17$, respectively. The first value progressively decreased with time, suggesting the internalisation of the targeted particles, which could be transported to lysosomes and degraded with the consequent release of free iodine, which was finally accumulated in the thyroid gland. On the contrary, the tumor uptake values remain almost unaltered for the non-targeted particles in the 12-36 $\mathrm{h}$ time window, while T/M values significantly increase at $t=36 \mathrm{~h}$. These previous results are more promising than our data, including those obtained with non-targeted particles, in which the tumor accumulation is ca. 15 times higher than the accumulation observed with our particles. The reason behind these differences is at the moment unclear, although it might be related to differences in particle size, surface charge (values not reported in [36]) or animal model and tumor size. The latter may have a huge impact in the results, as different pathophysiological features which vary among tumor models regulate the efficiency of EPR-mediated tumour targeting. These include intratumoural blood flow, angiogenic vascular permeability, tumour microenvironment, interstitial pressure and lymphatic drainage [71].

Other nanocarriers assayed so far in the context of BNCT are liposomes, which deserve special mention as they have been widely used in cancer therapy. For example, a delivery system consisting of polyethylene-glycol (PEG) binding liposomes (DPPC/cholesterol/DSPC-PEG2000) loaded with ${ }^{10} \mathrm{~B}$-enriched $\mathrm{BSH}$ showed tumour growth suppression in a mouse xenograft model of human pancreatic carcinoma [72]. The amount of ${ }^{10} \mathrm{~B}$ in the tumour was measured by prompt gamma-spectroscopy and reached values of $2.37 \mu \mathrm{g} / \mathrm{g}$ of tumour at $24 \mathrm{~h}$ after administration. In more recent works, BSH-encapsulating liposomes containing lipophilic boron compounds embedded in the bilayer have been developed and evaluated as BNCT agents in a mouse xenograft model of colon cancer. The amount of boron accumulated in the tumour was evaluated by inductively coupled plasma atomic emission spectroscopy (ICP-AES) at different administered doses. Maximum tumour accumulation was achieved at $36 \mathrm{~h}$ after administration, with values close to $175 \mu \mathrm{g} / \mathrm{g}$ of tumour when the administered dose was $50 \mathrm{mg} \mathrm{B} / \mathrm{kg}$, corresponding to $17.5 \% \mathrm{ID} / \mathrm{g}$ (assuming a mouse weight of $20 \mathrm{~g}$ ) [73]. The tumour accumulation was exceedingly higher that that achieved in our case (ca. 3000 times higher) although the administered dose was also ca. 250 times higher).

Other nanocarriers such as carbon nanotubes (CNTs) have been also investigated. In one of the pioneering works, substituted carborane cages were attached to the side walls of single wall carbon nanotubes (SWCNTs) and evaluated in a xenograft mouse model of mammary carcinoma, resulting 
in tumour accumulation values close to $23 \mu \mathrm{g} / \mathrm{g}$ of tumour as determined by inductively coupled plasma-optical emission spectrometry (ICP-OES) [74].

Inorganic NPs have been also assayed as BNCT drug candidates. For example, magnetic NPs functionalised with $o$-carborane were prepared and evaluated in a mouse model of breast cancer. Taking advantage of the magnetic properties of the particles, high tumour accumulation $(51.4 \mu \mathrm{g} / \mathrm{g}$ tumor) could be obtained under the influence of an external magnetic field (1.14 T), corresponding to $\mathrm{ca} .3 \% \mathrm{ID} / \mathrm{cm}^{3}$ [75]. However, the application of this approach to real clinical scenarios might be unfeasible, especially in the presence of metastasis.

Other examples of nanosystems engineered for boron delivery into tumour tissue have been reported and recently reviewed [76]. Different degrees of tumour accumulation have been achieved in different tumour models and experimental approaches. However, the diversity of tumour models and experimental conditions limits direct comparison with our results, as tumour accumulation, which ultimately relies solely in EPR effect, is severely affected by the physiology of the tumour.

To the best of our knowledge, our work constitutes the first example of in vivo evaluation of gold nanoparticles functionalised with COSAN moieties as boron carriers for BNCT. In spite of the fact that poor tumour accumulation was achieved, appropriate redesign of the core in terms of size and shape should lead to improved results. We anticipate that the use of smaller particles or nanorod-shaped particles should lead to lower sequestration by the liver as previously reported [70], thus increasing circulation time and facilitating tumour accumulation. Additionally, gold nanorods present the well-known ability to absorb near infrared (NIR) light, enabling photo-thermal therapy and paving thus the way towards combined therapies. Last but not least, our labelling strategies enable the determination of the location of the NPs in vivo, in real time and with high sensitivity, reducing thus the number of animals required for the fast investigation of new nanosystems as BNCT drug candidates.

\section{Materials and Methods}

\subsection{Reagents}

Cesium cobalt(III) bis(dicarbollide) (COSAN) (Katchem Ltd., Prague, Czech Republic), Gold(III) chloride trihydrate $\left(\mathrm{HAuCl}_{4} \cdot 3 \mathrm{H}_{2} \mathrm{O}\right.$, Aldrich, Madrid, Spain), Sodium citrate (Sigma-Aldrich, St. Louis, MO, USA) and poly (ethylene glycol) methyl ether thiol (MW 5000, Sigma-Aldrich) were used as purchased. All other reagents and anhydrous solvents, stored over $4 \AA$ molecular sieves, were purchased from Aldrich Chemical Co. (Madrid, Spain) and used without further purification. HPLC grade ethanol, methanol, and acetonitrile were purchased from Scharlab (Sentmenat, Barcelona, Spain).

Experiments were carried out, except when noted, under a dry, oxygen-free dinitrogen atmosphere. Column chromatography was performed using silica gel 60 (Scharlab). Analytical thin layer chromatography (TLC) measurements were conducted with silica gel $60 \mathrm{~F}_{254}$ plates (Macherey-Nagel, Hoerdt, France); and the spots were visualized under UV lamp. Compound 2 was prepared and characterized according to the previously reported protocol [40].

\subsection{Instrumentation}

The ${ }^{1} \mathrm{H}-\mathrm{NMR}(500 \mathrm{MHz}),{ }^{13} \mathrm{C}-\mathrm{NMR}(126 \mathrm{MHz})$ and ${ }^{11} \mathrm{~B}-\mathrm{NMR}(160 \mathrm{MHz})$ spectra were recorded on a 500-MHz Avance III spectrometer (Bruker BioSpin, Switzerland). All NMR spectra were performed in deuterated solvents at $22{ }^{\circ} \mathrm{C}$. The ${ }^{11} \mathrm{~B}-\mathrm{NMR}$ shifts were referenced to external $\mathrm{BF}_{3} \cdot \mathrm{OEt}_{2}$, while the ${ }^{1} \mathrm{H}$ and ${ }^{13} \mathrm{C}$-NMR shifts were referenced to $\mathrm{SiMe}_{4}$. Chemical shifts are reported in units of parts per million downfield from the reference, and all coupling constants are reported in Hertz.

UPLC/ESI-MS analyses were performed using an AQUITY UPLC separation module coupled to a LCT TOF Premier XE mass spectrometer (Waters, Manchester, UK). An Acquity BEH C18 column $(1.7 \mu \mathrm{m}, 5 \mathrm{~mm}, 2.1 \mathrm{~mm})$ was used as stationary phase. The elution buffers were A (water and $0.1 \%$ formic acid) and B (Methanol and $0.1 \%$ formic acid). The column was eluted with a gradient: $t=0 \mathrm{~min}$, 
$95 \% \mathrm{~A}, 5 \% \mathrm{~B} ; \mathrm{t}=0.5 \mathrm{~min}, 95 \% \mathrm{~A}, 5 \% \mathrm{~B} ; \mathrm{t}=5.5 \mathrm{~min}, 25 \% \mathrm{~A}, 75 \% \mathrm{~B} ; \mathrm{t}=16 \mathrm{~min}, 1 \% \mathrm{~A}, 99 \% \mathrm{~B} ; \mathrm{t}=20 \mathrm{~min}, 1 \%$ $\mathrm{A}, 99 \% \mathrm{~B}$. Total run was $20 \mathrm{~min}$, injection volume was $5 \mu \mathrm{L}$ and the flow rate $300 \mu \mathrm{L} / \mathrm{min}$. The detection was carried out in both negative and positive ion mode, monitoring the most abundant isotope peaks from the mass spectra $\left(\mathrm{M}-\mathrm{H}^{+}\right)$or $\left(\mathrm{M}+\mathrm{H}^{+}\right)$.

Transmission electron microscopy (TEM) was performed using a JEOL JEM-1400 plus microscope (Jeol, Tokyo, Japan) working at $120 \mathrm{kV}$. The carbon film of copper grids (CF400-Cu) was treated under air plasma in a glow discharge system (K100X, Emitech, Kent, UK, 40 mA during 2 min) just before sample preparation. For TEM examinations, a single drop $(1 \mu \mathrm{L})$ of the NPs solution was placed onto a copper grid coated with a carbon film (Electron Microscopy Sciences, Hatfieled, PA, USA). After 1 min, the drop was removed with filter paper and the sample was incubated with $3 \mu \mathrm{L}$ of uranyl acetate $0.5 \%$ (3 $\mathrm{min})$.

XPS experiments were performed in a SPECS Sage HR 100 spectrometer (Berlin, Germany) with a non-monochromatic $X$ ray source (aluminium $\mathrm{K} \alpha$ line of $1486.6 \mathrm{eV}$ energy and $252 \mathrm{~W}$ ), placed perpendicular to the analyser axis and calibrated using the 3d5/2 line of Ag with a full width at half maximum (FWHM) of $1.1 \mathrm{eV}$. The selected resolution for the spectra was $15 \mathrm{eV}$ of Pass Energy and $0.15 \mathrm{eV} / \mathrm{step}$. All measurements were made in an ultra-high vacuum (UHV) chamber at a pressure around $6 \times 10^{-8}$ mbar. An electron flood gun was used for charge neutralisation. Gaussian Lorentzian functions were used for fittings (after a Shirley background correction) where the FWHM of all the peaks were constrained while the peak positions and areas were set free. Main C1s peak was used for charge reference and set at $284.8 \mathrm{eV}$.

ICP-MS measurements were performed on a Thermo iCAP Q ICP-MS (Thermo Fisher Scientific $\mathrm{GmbH}$, Bremen, Germany). An ASX-560 autosampler was coupled to the ICP-MS (CETAC Tech, Omaha, NE, USA). UV-Vis spectra were measured in an 8453 UV-Vis diode-array spectrophotometer (Agilent, Santa Clara, CA, USA). DLS and $\xi$-potential measurements were performed using a Malvern Zetasizer Nano ZS system (Malvern Instruments, Malvern, UK). The particle size measurement settings were: 3 measurements $/ 14$ runs/10s in scattered mode at $173^{\circ}$ angle. Measurements were conducted at $\mathrm{T}=25^{\circ} \mathrm{C}$ and neutral $\mathrm{pH}$. Raman characterization was performed with an InVia Raman Microscope (Renishaw, Gloucestershire, UK), using a $633 \mathrm{~nm}$ laser (50\% power) with 10× objective.

\subsection{Chemistry}

\subsubsection{Synthesis of $[3]^{-}$}

To a solution of $2(750 \mathrm{mg}, 1.209 \mathrm{mmol})$ in DMF $(8 \mathrm{~mL})$, potassium thioacetate $(165.7 \mathrm{mg}$, $1.451 \mathrm{mmol}$ ) was added and stirred at room temperature for $14 \mathrm{~h}$. For the workup, $50 \mathrm{~mL}$ of water was added and extracted with ethyl acetate $(3 \times 50 \mathrm{~mL})$; the organic layers were combined and washed with cold water and brine solution before drying over anhydrous sodium sulphate. The solvent was evaporated and the crude was purified using column chromatography (silica gel, $10 \% \mathrm{MeOH}$ in dichloromethane) to yield a [3] ${ }^{-}$as yellow solid (705 mg, 84\%). ${ }^{1} \mathrm{H}-\mathrm{NMR}$ (methanol- $\left.d_{4}\right) \delta 4.15$ $\left[\mathrm{C}_{\mathrm{c}}-\mathrm{H}, 2 \mathrm{H}, \mathrm{s}\right], 4.07\left[\mathrm{C}_{\mathrm{c}}-\mathrm{H}, 2 \mathrm{H}, \mathrm{s}\right], 3.49\left[\mathrm{CH}_{2} \mathrm{O}, 2 \mathrm{H}, \mathrm{t}\right], 2.87\left[\mathrm{CH}_{2}-\mathrm{S}, 2 \mathrm{H}, \mathrm{t}\right], 2.31\left[\mathrm{CH}_{3}, 3 \mathrm{H}, \mathrm{s}\right], 1.59-1.54$ $\left[\mathrm{CH}_{2}-\mathrm{CH}_{2}-\mathrm{O}, 2 \mathrm{H}, \mathrm{m}\right], 1.52-1.47\left[\mathrm{CH}_{2}-\mathrm{CH}_{2} \mathrm{~S}, 2 \mathrm{H}, \mathrm{m}\right], 1.42-1.37\left[\mathrm{CH}_{2}-\mathrm{CH}_{2} \mathrm{CH}_{2} \mathrm{O}, 2 \mathrm{H}, \mathrm{m}\right] ;{ }^{11} \mathrm{~B}-\mathrm{NMR}$ $\left(\right.$ methanol- $\left.d_{4}\right) \delta 23.03[1 \mathrm{~B}, \mathrm{~s}], 4.63\left[1 \mathrm{~B}, \mathrm{~d},{ }^{1} \mathrm{~J}(\mathrm{~B}-\mathrm{H})=140.3\right], 0.48\left[1 \mathrm{~B}, \mathrm{~d},{ }^{1} \mathrm{~J}(\mathrm{~B}-\mathrm{H})=143.3\right],-2.10[1 \mathrm{~B}$, $\left.\mathrm{d},{ }^{1} \mathrm{~J}(\mathrm{~B}-\mathrm{H})=142.8\right],-4.59\left[2 \mathrm{~B}, \mathrm{~d},{ }^{1} \mathrm{~J}(\mathrm{~B}-\mathrm{H})=138.7\right],-8.46[6 \mathrm{~B}, \mathrm{td}, \mathrm{J} 162.8,150.9,63.5],-17.22$ [2B, d, $\left.{ }^{1} \mathrm{~J}(\mathrm{~B}-\mathrm{H})=154.4\right],-20.42[2 \mathrm{~B}, \mathrm{~d}],-22.59[1 \mathrm{~B}, \mathrm{~d}],-28.26\left[1 \mathrm{~B}, \mathrm{~d},{ }^{1} \mathrm{~J}(\mathrm{~B}-\mathrm{H})=159.4\right] ;{ }^{13} \mathrm{C}-\mathrm{NMR}\left(\mathrm{methanol}^{-} d_{4}\right)$ : 188.24, 68.93, 53.54, 46.70, 30.89, 29.21, 29.14, 28.61, 25.10; LCMS (ESI) Experimental [M] $]^{-} \mathrm{m} / z=482.66$ (theoretical $[\mathrm{M}]^{-} \mathrm{m} / \mathrm{z}=482.98$ ).

\subsubsection{Synthesis of $[4]^{-}$}

To a solution of [3] $]^{-}(890 \mathrm{mg}, 1.440 \mathrm{mmol})$ in methanol $(30 \mathrm{~mL})$, sodium methoxide $(77.8 \mathrm{mg}$, $1.440 \mathrm{mmol}$ ) was added and stirred at room temperature for $14 \mathrm{~h}$. For the workup, reaction mixture was neutralized with IR-120 resin ( $3 \mathrm{~g})$, filtered and washed with $10 \mathrm{~mL}$ of methanol. Combined 
methanol layers were concentrated and purified using column chromatography (silica gel, $12 \% \mathrm{MeOH}$ in dichloromethane) to yield [4] $]^{-}$as a yellow solid (505 mg, 60.5\%). ${ }^{1} \mathrm{H}-\mathrm{NMR}$ (methanol- $\left.d_{4}\right) \delta 4.14$ $\left[\mathrm{C}_{\mathrm{c}}-\mathrm{H}, 2 \mathrm{H}, \mathrm{bs}\right], 4.06\left[\mathrm{C}_{\mathrm{c}}-\mathrm{H}, 2 \mathrm{H}, \mathrm{bs}\right], 3.51\left[\mathrm{CH}_{2} \mathrm{O}, 2 \mathrm{H}, \mathrm{t}\right], 2.50\left[\mathrm{CH}_{2}-\mathrm{S}, 2 \mathrm{H}, \mathrm{t}\right], 1.60\left[\mathrm{CH}_{2}-\mathrm{CH}_{2}-\mathrm{O}, 2 \mathrm{H}, \mathrm{p}\right]$, $1.58,1.53\left[\mathrm{CH}_{2}-\mathrm{CH}_{2} \mathrm{~S}, 2 \mathrm{H}, \mathrm{dq}\right], 1.42\left[\mathrm{CH}_{2}-\mathrm{CH}_{2} \mathrm{CH}_{2} \mathrm{O}, 2 \mathrm{H}, \mathrm{qd}\right] ;{ }^{11} \mathrm{~B}-\mathrm{NMR}$ (methanol- $\left.d_{4}\right) \delta 23.02[1 \mathrm{~B}, \mathrm{~s}]$, $4.64\left[1 \mathrm{~B}, \mathrm{~d},{ }^{1} \mathrm{~J}(\mathrm{~B}-\mathrm{H})=140.0\right], 0.52\left[1 \mathrm{~B}, \mathrm{~d},{ }^{1} \mathrm{~J}(\mathrm{~B}-\mathrm{H})=142.0\right],-2.11\left[1 \mathrm{~B}, \mathrm{~d},{ }^{1} \mathrm{~J}(\mathrm{~B}-\mathrm{H})=144.5\right],-4.56[2 \mathrm{~B}, \mathrm{~d}$, $\left.{ }^{1} \mathrm{~J}(\mathrm{~B}-\mathrm{H})=142.4\right],-7.41[6 \mathrm{~B}, \mathrm{~m}],-17.20\left[2 \mathrm{~B}, \mathrm{~d},{ }^{1} \mathrm{~J}(\mathrm{~B}-\mathrm{H})=157.7\right],-20.46\left[2 \mathrm{~B}, \mathrm{~d},{ }^{1} \mathrm{~J}(\mathrm{~B}-\mathrm{H})=159.0\right],-22.05$

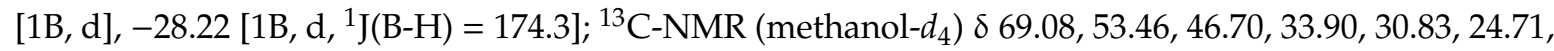
23.65. LCMS (ESI) Experimental $[\mathrm{M}]^{-} \mathrm{m} / z=440.52$ (theoretical $[\mathrm{M}]^{-} \mathrm{m} / \mathrm{z}=440.94$ ).

\subsubsection{Synthesis of $[5]^{-}$}

To a solution of [3] $]^{-}(50 \mathrm{mg}, 0.081 \mathrm{mmol})$ in acetonitrile $(2 \mathrm{~mL})$, chloramine- $\mathrm{T}(37 \mathrm{mg}, 0.129 \mathrm{mmol})$, sodium iodide $(15 \mathrm{mg}, 0.097 \mathrm{mmol})$ and acetic acid $(130 \mu \mathrm{L})$ were added. The reaction mixture was allowed to stir at room temperature for $10 \mathrm{~h}$. For the workup, $20 \mathrm{~mL}$ of water were added and extracted with ethyl acetate $(3 \times 15 \mathrm{~mL})$, the organic layers were combined and washed with brine solution before drying over anhydrous sodium sulphate. The solvent was evaporated and the crude was purified using column chromatography (silica gel, $10 \% \mathrm{MeOH}$ in dichloromethane) to yield [5] ${ }^{-}$as a yellow

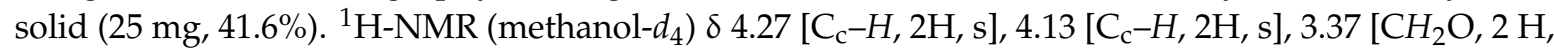
t], $2.85\left[\mathrm{CH}_{2}-\mathrm{S}, 2 \mathrm{H}, \mathrm{t}\right], 2.31\left[\mathrm{CH}_{3}, 3 \mathrm{H}, \mathrm{s}\right], 1.55\left[\mathrm{CH}_{2}-\mathrm{CH}_{2}-\mathrm{O}, 2 \mathrm{H}, \mathrm{m}\right], 1.45\left[\mathrm{CH}_{2}-\mathrm{CH}_{2} \mathrm{~S}, 2 \mathrm{H}, \mathrm{m}\right], 1.36$ $\left[\mathrm{CH}_{2}-\mathrm{CH}_{2} \mathrm{CH}_{2} \mathrm{O}, 2 \mathrm{H}, \mathrm{m}\right] ;{ }^{11} \mathrm{~B}-\mathrm{NMR}$ (methanol-d $\left.\mathrm{d}_{4}\right) \delta 21.47[1 \mathrm{~B}, \mathrm{~s}],-0.42\left[2 \mathrm{~B}, \mathrm{~d},{ }^{1} \mathrm{~J}(\mathrm{~B}-\mathrm{H})=145.4\right],-4.39$ $[1 \mathrm{~B}, \mathrm{~s}],-5.71\left[4 \mathrm{~B}, \mathrm{~d},{ }^{1} \mathrm{~J}(\mathrm{~B}-\mathrm{H})=140.0\right],-7.27\left[4 \mathrm{~B}, \mathrm{~d},{ }^{1} \mathrm{~J}(\mathrm{~B}-\mathrm{H})=152.8\right],-18.07\left[2 \mathrm{~B}, \mathrm{~d},{ }^{1} \mathrm{~J}(\mathrm{~B}-\mathrm{H})=152.4\right]$, $-20.04\left[2 \mathrm{~B}, \mathrm{~d},{ }^{1} \mathrm{~J}(\mathrm{~B}-\mathrm{H})=161.3\right],-23.45\left[1 \mathrm{~B}, \mathrm{~d},{ }^{1} \mathrm{~J}(\mathrm{~B}-\mathrm{H})=161.3\right],-27.37\left[1 \mathrm{~B}, \mathrm{~d},{ }^{1} \mathrm{~J}(\mathrm{~B}-\mathrm{H})=170.4\right] ;{ }^{13} \mathrm{C}-\mathrm{NMR}$ $\left(\mathrm{CDCl}_{3}\right) \delta 191.05,70.24,58.99,56.52,34.78,33.10,32.97,32.52,29.24$. LCMS (ESI) Experimental [M] ${ }^{-}$ $m / z=606.6$ (theoretical $[\mathrm{M}]^{-} m / z=607.6$ ).

\subsubsection{Synthesis of $[6]^{-}$}

To a solution of $[5]^{-}(9 \mathrm{mg}, 0.0144 \mathrm{mmol})$ in methanol $(3 \mathrm{~mL})$, sodium methoxide $(1 \mathrm{mg}, 0.0144 \mathrm{mmol})$ was added and the resulting solution was allowed to stir at room temperature for $14 \mathrm{~h}$. For the workup, the reaction mixture was neutralized with IR-120 resin $(100 \mathrm{mg})$, filtered and washed with $2 \mathrm{~mL}$ of methanol. The combined methanol layer was concentrated and the residue was purified using column chromatography (silica gel, $12 \% \mathrm{MeOH}$ in dichloromethane) to yield [6] ${ }^{-}$as a yellow solid (4.5 $\mathrm{mg}$, 55\%). ${ }^{1} \mathrm{H}-\mathrm{NMR}$ (methanol- $\left.d_{4}\right) \delta 4.28\left[\mathrm{C}_{\mathrm{c}}-\mathrm{H}, 2 \mathrm{H}, \mathrm{s}\right], 4.14\left[\mathrm{C}_{\mathrm{c}}-\mathrm{H}, 2 \mathrm{H}, \mathrm{s}\right], 3.40\left[\mathrm{CH}_{2} \mathrm{O}, 2 \mathrm{H}, \mathrm{t}\right], 2.67\left[\mathrm{CH}_{2}-\mathrm{S}\right.$, $2 \mathrm{H}, \mathrm{t}], 1.66\left[\mathrm{CH}_{2}-\mathrm{CH}_{2}-\mathrm{O}, 2 \mathrm{H}, \mathrm{m}\right], 1.46\left[\mathrm{CH}_{2}-\mathrm{CH}_{2} \mathrm{~S}, 2 \mathrm{H}, \mathrm{q}\right], 1.38\left[\mathrm{CH}_{2}-\mathrm{CH}_{2} \mathrm{CH}_{2} \mathrm{O}, 2 \mathrm{H}, \mathrm{m}\right] ;{ }^{11} \mathrm{~B}-\mathrm{NMR}$

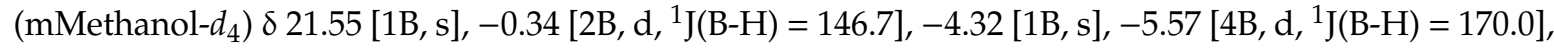
$-6.90[4 \mathrm{~B}, \mathrm{~d}],-17.94\left[2 \mathrm{~B}, \mathrm{~d},{ }^{1} \mathrm{~J}(\mathrm{~B}-\mathrm{H})=167.3\right],-20.58\left[2 \mathrm{~B}, \mathrm{~d},{ }^{1} \mathrm{~J}(\mathrm{~B}-\mathrm{H})=153.2\right],-23.13\left[2 \mathrm{~B}, \mathrm{~d},{ }^{1} \mathrm{~J}(\mathrm{~B}-\mathrm{H})=\right.$

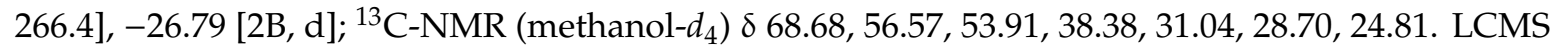
(ESI) Experimental $[\mathrm{M}]^{-} m / z=566.64$ (theoretical $[\mathrm{M}]^{-} \mathrm{m} / z=566.84$ ).

\subsection{Radiochemistry}

\subsubsection{Synthesis of ${ }^{124} \mathrm{I}-[5]^{-}$}

Acetonitrile $(200 \mu \mathrm{L})$ was added to $\mathrm{Na}\left[{ }^{124} \mathrm{I}\right] \mathrm{I}(50 \mu \mathrm{L}, 37 \mathrm{MBq})$ and the resulting solution was introduced in a $2.5 \mathrm{~mL}$ conic vial. The solvent was evaporated to dryness $\left(100{ }^{\circ} \mathrm{C}, 5 \mathrm{~min}\right.$, constant helium flow at $20 \mathrm{~mL} / \mathrm{min})$ and $1 \mathrm{mg}$ of [5] ${ }^{-}$dissolved in acetonitrile $(100 \mu \mathrm{L})$ was added together with trans-bis(acetate)bis[o-(di-o-tolylphosphino)benzyl] dipalladium (II) (Herrmann's catalyst, HC, 0.1 mg, $0.101 \mu \mathrm{mol})$ dissolved in toluene $(100 \mu \mathrm{L})$. The reaction mixture was heated at $100{ }^{\circ} \mathrm{C}$ for $5 \mathrm{~min}$, the solvent was removed under a constant helium flow and the resulting solid was dissolved in $0.5 \mathrm{~mL}$

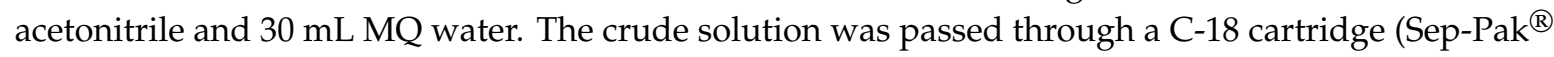
Light, Waters, Milford, MA, USA) and washed with MQ water ( $5 \mathrm{~mL} \times 2)$ to remove free iodine-124. The desired labelled compound $\left({ }^{124} \mathrm{I}-[5]^{-}\right)$was eluted from the cartridge with ethanol $(500 \mu \mathrm{L})$ and the solvent was evaporated to dryness. Quality control was performed by radio-HPLC after diluting the 
solid residue with mobile phase. Analytical conditions were: Stationary phase: Mediterranea Sea18 column $(4.6 \times 150 \mathrm{~mm}, 5 \mu \mathrm{m}$ particle size, Teknokroma, Barcelona, Spain); mobile phase A: $0.1 \mathrm{M}$ ammonium formate $(\mathrm{AMF})$ buffer $\mathrm{pH}=3.9$; $\mathrm{B}$ : acetonitrile; flow rate $=1 \mathrm{~mL} / \mathrm{min}$; gradient: $0 \mathrm{~min}: 60 \%$ A- 40\% B; 2 min: 60\% A- 40\% B; 6 min: 20\% A- 80\% B; $14 \min : 0 \%$ A- 100\% B; 16 min: 0\% A- 100\% B; $18 \mathrm{~min}: 60 \%$ A- 40\% B; $20 \mathrm{~min}: 60 \%$ A- 40\% B (retention time: $11.5 \mathrm{~min}$ ).

\subsubsection{Synthesis of ${ }^{124} \mathrm{I}-[6]^{-}$}

Dry ${ }^{124} \mathrm{I}-[5]^{-}$obtained from the previous step was dissolved in $250 \mu \mathrm{L}$ of methanol. Sodium methoxide ( $2 \mathrm{mg}$ ) was added and stirred at room temperature for $6 \mathrm{~h}$. After Complete hydrolysis, confirmed by analytical radio-HPLC, reformulation was carried out by dilution with water, retention on a C-18 cartridge (Sep-Pak ${ }^{\circledR}$ Light, Waters), further elution with ethanol (500 $\mu \mathrm{L}$, Sigma-Aldrich) and evaporation to dryness. Quality control was performed by HPLC. Analytical conditions were: Stationary phase: Mediterranea Sea18 column $(4.6 \times 150 \mathrm{~mm}, 5 \mu \mathrm{m}$ particle size, Teknokroma); mobile phase A: $0.1 \mathrm{M}$ ammonium formate $(\mathrm{AMF})$ buffer $\mathrm{pH}=3.9$; $\mathrm{B}$ : acetonitrile; flow rate $=1 \mathrm{~mL} / \mathrm{min}$; gradient: 0 min: 60\% A- 40\% B; 2 min: 60\% A- 40\% B; 6 min: 20\% A- 80\% B; 14 min: 0\% A- 100\% B; 16 min: 0\% A- 100\% B; 18 min: 60\% A- 40\% B; 20 min: 60\% A- 40\% B (retention time: $13.1 \mathrm{~min}$ ).

\subsection{Preparation of $A u N P s$}

\subsubsection{Synthesis of Citrate-Stabilized Gold NPs (CIT-AuNPs)}

AuNPs-Citrate with an averaged diameter 18-20 nm and with Au concentration of $1 \mathrm{mg} / \mathrm{mL}$ were synthesized following the Turkevich method [44]. In brief, $97.1 \mathrm{mg}$ ( $0.33 \mathrm{mmol})$ trisodium citrate dihydrate were dissolved in $150 \mathrm{~mL}$ water (concentration $=2.2 \mathrm{mM}$ ) and the solution was heated to reflux in a $250 \mathrm{~mL}$ three-necked flask equipped with a Dimroth condenser. The boiling time before addition of the precursor was $15 \mathrm{~min} .1 \mathrm{~mL}$ precursor solution ( $\mathrm{HAuCl}_{4} \cdot 3 \mathrm{H}_{2} \mathrm{O}$ in water, $25 \mathrm{mM}$ ) was then quickly injected under rapid stirring. When the colour of the solution changed to the characteristic wine-red, which indicates formation of AuNPs, the heating-mantle was switched off but not removed until the temperature of the solution was $70^{\circ} \mathrm{C}$. The resulting NPs were centrifuged at $12,000 \times g$ for $20 \mathrm{~min}$ to remove free citrate and resuspended in ultrapure water.

\subsubsection{Synthesis of PEG-Stabilized, COSAN-Functionalized AuNPs (PEG-AuNPs@[4]-)}

AuNPs-Citrate prepared as described above $(2 \mathrm{~mL})$ were place into a vial. Then $100 \mu \mathrm{L}$ of PEG (3 $\mathrm{mg} / \mathrm{mL}$ ) were slowly added under vigorous stirring. After $15 \mathrm{~min}, 100 \mu \mathrm{L}$ of a fresh solution of [4] ${ }^{-}$in ethanol ( $3 \mathrm{mg} / \mathrm{mL})$ were quickly added and stirring was maintained for $2 \mathrm{~h}$. The resulting NPs were centrifuged at $12,000 \times g$ for $25 \mathrm{~min}$ and resuspended in ultrapure water three times.

\subsubsection{Synthesis of PEG-AuNPs@[4]- Labelled at the Core}

AuNPs-Citrate prepared as described above $(2 \mathrm{~mL})$ were placed into a vial. $\left[{ }^{124} \mathrm{I}\right] \mathrm{NaI}(15 \mu \mathrm{L}$, solution in $0.1 \mathrm{M} \mathrm{NaOH})$ was added and the solution was stirred for $10 \mathrm{~min}$. Then, PEG (100 $\mu \mathrm{L}$, $3 \mathrm{mg} / \mathrm{mL}$ ) was slowly added under vigorous stirring. After $15 \mathrm{~min}, 100 \mu \mathrm{L}$ of a fresh solution of [4] ${ }^{-}$in ethanol ( $3 \mathrm{mg} / \mathrm{mL})$ were quickly added and stirring was maintained for $2 \mathrm{~h}$. The resulting NPs were centrifuged at $12,000 \times g$ for $25 \mathrm{~min}$ and resuspended in ultrapure water three times. Radiochemical incorporation ratios around $98 \%$ were obtained.

\subsubsection{Synthesis of PEG-AuNPs@[4] ${ }^{-}$Labelled at the Shell}

$2 \mathrm{~mL}$ of AuNPs-Citrate prepared as described above were placed into a vial. Then, PEG $(100 \mu \mathrm{L}$, $3 \mathrm{mg} / \mathrm{mL}$ ) was slowly added under vigorous stirring. After $15 \mathrm{~min}, 100 \mu \mathrm{L}$ of a fresh solution of [4] $]^{-}$in ethanol $(3 \mathrm{mg} / \mathrm{mL})$ and freshly prepared ${ }^{124} \mathrm{I}-[6]^{-}(22.2 \mathrm{MBq})$ dissolved in ethanol $(15 \mu \mathrm{L})$ were quickly added and stirring was maintained for $2 \mathrm{~h}$. The resulting NPs were centrifuged at $12,000 \times g$ for $25 \mathrm{~min}$ 
and resuspended in ultrapure water three times. Radiochemical incorporation ratios around 55\% were obtained.

\subsection{In Vivo Studies}

Animals were maintained and handled in accordance with the Guidelines for Accommodation and Care of Animals (European Convention for the Protection of Vertebrate Animals Used for Experimental and Other Scientific Purposes). All animal procedures were performed in accordance with the Spanish policy for animal protection (RD53/2013), which meets the requirements of the European Union Animal Directive (2010/63/EU). Experimental procedures were approved by Ethical Committee of CIC biomaGUNE.

PET studies with labelled NPs were carried out in mice ( $n=2$ per compound) using an eXplore Vista-CT small animal PET-CT system (GE Healthcare, Chicago, IL, USA). Anaesthesia was induced with $3 \%$ isoflurane and maintained by 1.5 to $2 \%$ of isoflurane in $100 \% \mathrm{O}_{2}$. For intravenous administration of the radiotracer, the tail vein was catheterized with a 24-gauge catheter and the labelled NPs $(3.8 \pm 0.6 \mathrm{MBq}$ for NPs labelled at the core; $2.7 \pm 0.3 \mathrm{MBq}$ for NPs labelled at the shell, volume $=150 \mu \mathrm{L})$ were injected concomitantly with the start of a PET dynamic acquisition. Mice were kept normothermic throughout the scans using a heating blanket (Homeothermic Blanket Control Unit, Bruker BioSpin $\mathrm{GmbH}$, Karlsruhe, Germany).

Whole body scans were acquired just after administration during $60 \mathrm{~min}$. At time points $10 \mathrm{~h}, 24 \mathrm{~h}$, $72 \mathrm{~h}$ and $144 \mathrm{~h}, 30 \mathrm{~min}$ acquisitions were performed. All the scans were recorded in the $400-700 \mathrm{KeV}$ energetic window. CT acquisitions were also performed at the end of each PET scan, providing anatomical information for unambiguous localisation of the radioactive signal. After the last imaging session, animals were sacrificed and the liver was harvested for further processing.

PET images were reconstructed (decay and CT-based attenuation corrected) with filtered back projection (FBP) using a Ramp filter with a cut off frequency of $1 \mathrm{~Hz}$. Images were analysed using PMOD image analysis software (version 3.4, PMOD Technologies Ltd., Zürich, Switzerland). With that aim, volumes of interest (VOIs) were manually drawn in the lungs, liver, bladder, stomach, kidneys, spleen, tumour, heart and thyroid gland using the CT images as anatomical reference. VOIs were then transferred to the PET images and time activity curves (decay corrected) were obtained for each organ as $\mathrm{cps} / \mathrm{cm}^{3}$. Curves were transformed into real activity $\left(\mathrm{Bq} / \mathrm{cm}^{3}\right)$ curves. Injected dose normalization was finally applied to data to get time activity curves as percentage of injected dose per $\mathrm{cm}^{3}$ of tissue.

\subsection{Ex Vivo Studies}

Ion beam microscopy (IBM) studies were performed at the LIPSION nanoprobe at Leipzig University using a $2.25 \mathrm{MeV}$ proton beam with a spot size of approximately $1 \mu \mathrm{m}$ and supplied by Singletron ${ }^{\mathrm{TM}}$ particle accelerator (HVEE, Amersfoort, NL). Under vacuum of $10^{-6}$ Torr two ion beam microscope techniques, such as micro-proton induced X-ray emission ( $\mu$ PIXE) and micro-Rutherford backscattering $(\mu R B S)$, were used simultaneously to study the spatial distribution of elements originated from tissue and NPs. Extracted $\mu$ RBS spectra from the region of interest were analyzed by using SIMNRA 6.06 software (Dr. Matej Mayer, MPI of plasmaphysic, Garching, GE) to determine accumulated charge, area density (atoms $/ \mathrm{cm}^{2}$ ) and element matrix composition $(\mathrm{C}, \mathrm{N}, \mathrm{O})$. These parameters were used as input for $\mu$ PIXE analysis by means of GeoPIXE 5.1 software (CSIRO Earth Science and Resource Engineering, Clayton, Australia) to quantify element concentration in the tissue of NP treated mice. The detailed procedure is described elsewhere [61,77].

Confocal Raman microspectroscopy (CRM) analyses were performed using an Alpha300 R microscope (WITec GmbH, Ulm, Germany) equipped with a $532 \mathrm{~nm}$ laser source, a $600 \mathrm{~g} \mathrm{~mm}^{-1}$ grating and a charge-coupled device (CCD) cooled down to $-61^{\circ} \mathrm{C}$. All measurements were conducted using a $63 x$ water immersion objective (W Plan-Apochromat 63x/1.0, Zeiss, Oberkochen, Germany). Raman spectra were collected pixel-wise in $x-y$ plane with an integration time of about $70 \mu \mathrm{s}$. Acquired spectra were processed using the Project FOUR PLUS 4.0 software (WITec GmbH, Ulm, Germany). 


\section{Conclusions}

Size and shape-tuned gold NPs (AuNPs) stabilised with polyethylene glycol (PEG) and functionalized with the boron-rich anion cobalt bis(dicarbollide) have been prepared and characterised. The incorporation of the positron emitter ${ }^{124}$ I either at the core or at the shell of the NPs enabled the determination of the in vivo biodistribution in a xenograft mouse model of human fibroblastoma. The NPs showed good in vivo stability but poor accumulation in the tumour. These results suggest that appropriate modification of the gold core in terms of size and shape is required in order to develop promising BNCT drug candidates.

Supplementary Materials: The following are available online, Figure S1: ${ }^{1} \mathrm{H}-\mathrm{NMR}$ of $[3]^{-}$, Figure S2: ${ }^{11} \mathrm{~B}-\mathrm{NMR}$ of $[3]^{-}$; Figure S3: ${ }^{13} \mathrm{C}-\mathrm{NMR}$ of $[3]^{-}$; Figure S4: ${ }^{1} \mathrm{H}-\mathrm{NMR}$ of $[4]^{-}$; Figure S5: ${ }^{11} \mathrm{~B}-\mathrm{NMR}$ of $[4]^{-}$; Figure S6: ${ }^{13} \mathrm{C}-\mathrm{NMR}$ of [4] ${ }^{-}$; Figure S7: ${ }^{1} \mathrm{H}-\mathrm{NMR}$ of $[5]^{-}$; Figure S8: ${ }^{11} \mathrm{~B}-\mathrm{NMR}$ of $[5]^{-}$; Figure S9: ${ }^{13} \mathrm{C}-\mathrm{NMR}$ of [5] ${ }^{-}$; Figure S10: ${ }^{1} \mathrm{H}-\mathrm{NMR}$ of $[6]^{-}$; Figure S11: ${ }^{11} \mathrm{~B}-\mathrm{NMR}$ of $[6]^{-}$; Figure S12: ${ }^{13} \mathrm{C}-\mathrm{NMR}$ of $[6]^{-}$.

Author Contributions: Conceptualization, J.L., V.G.-V. and K.R.P.; methodology, J.L., V.G.-V. and K.R.P.; investigation, K.R.P., K.B.G., U.C., Z.B., J.M., I.E.-L., C.Z.; resources, J.L.; data curation, J.L., K.R.P.; Writing—Original Draft preparation, K.R.P.; Writing—Review and Editing, J.L., V.G.-V.; supervision, J.L.; funding acquisition, J.L.

Funding: This research was funded by The Spanish Ministry of Economy and Competitiveness, grant number CTQ2017-87637-R.

Conflicts of Interest: The authors declare no conflict of interest.

\section{References}

1. Ferlay, J.; Soerjomataram, I.; Ervik, M.; Dikshit, R.; Eser, S.; Mathers, C.; Rebelo, M.; Parkin, D.M.; Forman, D.; Bray, F. GLOBOCAN 2012 v1.0. Available online: http://globocan.iarc.fr. (accessed on 15 May 2013).

2. Hally, C.; Rodríguez-Amigo, B.; Bresolí-Obach, R.; Planas, O.; Nos, J.; Boix-Garriga, E.; Ruiz-González, R.; Nonell, S. CHAPTER 4: Photodynamic Therapy. In RSC Drug Discovery Series; CRC Press: Boca Raton, FL, USA, 2018; Volume 2018, pp. 86-122.

3. Nomoto, T.; Nishiyama, N. Photodynamic therapy. In Photochemistry for Biomedical Applications: From Device Fabrication to Diagnosis and Therapy; Springer: Berlin, Germany, 2018; pp. 301-313.

4. England, C.G.; Cai, W. Theranostic nanoparticles for photothermal therapy of cancer. In Hybrid Nanomaterials: Design, Synthesis, and Biomedical Applications; CRC Press: Boca Raton, FL, USA, 2017; pp. 305-333.

5. Liu, Z.; Chen, Z. Near infrared nanomaterials for photothermal therapy. In RSC Nanoscience and Nanotechnology; CRC Press: Boca Raton, FL, USA, 2016; Volume 2016, pp. 277-321.

6. Locher, G.L. Biological effects and therapeutic possibilities of neutrons. Amer. J. Roentgenol. Radium Therapy Nucl. Med. 1936, 36, 1-13.

7. Bregadze, V.I.; Sivaev, I.B. Polyhedral boron compounds for BNCT. In Boron Science: New Technologies and Applications; CRC Press: Boca Raton, FL, USA, 2016; pp. 181-207.

8. Nakamura, H.; Kirihata, M. Boron compounds: New candidates for boron carriers in BNCT. In Neutron Capture Therapy: Principles and Applications; Springer Science \& Business Media: Berlin, Germany, 2012; Volume 9783642313349, pp. 99-116.

9. Yokoyama, K.; Miyatake, S.I.; Kajimoto, Y.; Kawabata, S.; Doi, A.; Yoshida, T.; Asano, T.; Kirihata, M.; Ono, K.; Kuroiwa, T. Pharmacokinetic study of BSH and BPA in simultaneous use for BNCT. J. Neurooncol. 2006, 78, 227-232. [CrossRef] [PubMed]

10. Sauerwein, W.A.G.; Bet, P.M.; Wittig, A. Drugs for BNCT: BSH and BPA. In Neutron Capture Therapy: Principles and Applications; Springer Science \& Business Media: Berlin, Germany, 2012; Volume 9783642313349, pp. 117-160.

11. Kueffer, P.J.; Maitz, C.A.; Khan, A.A.; Schuster, S.A.; Shlyakhtina, N.I.; Jalisatgi, S.S.; Brockman, J.D.; Nigg, D.W.; Hawthorne, M.F. Boron neutron capture therapy demonstrated in mice bearing EMT6 tumors following selective delivery of boron by rationally designed liposomes. Proc. Natl. Acad. Sci. USA 2013, 110, 6512-6517. [CrossRef] [PubMed] 
12. Maitz, C.A.; Khan, A.A.; Kueffer, P.J.; Brockman, J.D.; Dixson, J.; Jalisatgi, S.S.; Nigg, D.W.; Everett, T.A.; Hawthorne, M.F. Validation and Comparison of the Therapeutic Efficacy of Boron Neutron Capture Therapy Mediated By Boron-Rich Liposomes in Multiple Murine Tumor Models. Translational Oncol. 2017, 10, 686-692. [CrossRef] [PubMed]

13. Tachikawa, S.; Miyoshi, T.; Koganei, H.; El-Zaria, M.E.; Viñas, C.; Suzuki, M.; Ono, K.; Nakamura, H. Spermidinium closo-dodecaborate-encapsulating liposomes as efficient boron delivery vehicles for neutron capture therapy. Chem. Commun. 2014, 50, 12325-12328. [CrossRef] [PubMed]

14. Takeuchi, I.; Kishi, N.; Shiokawa, K.; Uchiro, H.; Makino, K. Polyborane encapsulated liposomes prepared using $\mathrm{pH}$ gradient and reverse-phase evaporation for boron neutron capture therapy: biodistribution in tumor-bearing mice. Colloid. Polym. Sci. 2018, 296, 1137-1144. [CrossRef]

15. Takeuchi, I.; Tomoda, K.; Matsumoto, K.; Uchiro, H.; Makino, K. PEGylated liposomes prepared with polyborane instead of cholesterol for BNCT: characteristics and biodistribution evaluation. Colloid. Polym. Sci. 2016, 294, 1679-1685. [CrossRef]

16. Yannopoulos, S.N.; Zouganelis, G.D.; Nurmohamed, S.; Smith, J.R.; Bouropoulos, N.; Calabrese, G.; Fatouros, D.G.; Tsibouklis, J. Physisorbed o-carborane onto lyso-phosphatidylcholine-functionalized, single-walled carbon nanotubes: A potential carrier system for the therapeutic delivery of boron. Nanotechnology 2010, 21, 085101. [CrossRef] [PubMed]

17. Ferreira, T.H.; Miranda, M.C.; Rocha, Z.; Leal, A.S.; Gomes, D.A.; Sousa, E.M.B. An assessment of the potential use of BNNTs for boron neutron capture therapy. Nanomaterials 2017, 7. [CrossRef]

18. da Silva, W.M.; Hilário Ferreira, T.; de Morais, C.A.; Soares Leal, A.; Barros Sousa, E.M. Samarium doped boron nitride nanotubes. Appl. Radiat. Isot. 2018, 131, 30-35. [CrossRef]

19. Iizumi, Y.; Okazaki, T.; Zhang, M.; Yuge, R.; Ichihashi, T.; Nakamura, M.; Ikehara, Y.; Iijima, S.; Yudasaka, M. Preparation and functionalization of boron nitride containing carbon nanohorns for boron neutron capture therapy. Carbon 2015, 93, 595-603. [CrossRef]

20. Singh, B.; Kaur, G.; Singh, P.; Singh, K.; Kumar, B.; Vij, A.; Kumar, M.; Bala, R.; Meena, R.; Singh, A.; et al. Nanostructured Boron Nitride with High Water Dispersibility for Boron Neutron Capture Therapy. Sci. Rep. 2016, 6, 35535. [CrossRef] [PubMed]

21. Tietze, R.; Unterweger, H.; Dürr, S.; Lyer, S.; Canella, L.; Kudejova, P.; Wagner, F.M.; Petry, W.; Taccardi, N.; Alexiou, $\mathrm{C}$. Boron containing magnetic nanoparticles for neutron capture therapy-an innovative approach for specifically targeting tumors. Appl. Radiat. Isot. 2015, 106, 151-155. [CrossRef] [PubMed]

22. Wang, W.; Lin, J.; Xing, C.; Chai, R.; Abbas, S.; Song, T.; Tang, C.; Huang, $\mathrm{Y}_{\mathrm{Fe}} \mathrm{Fe}_{3} \mathrm{O}_{4}$ nanoparticle-coated boron nitride nanospheres: Synthesis, magnetic property and biocompatibility study. Ceram. Int. 2017, 43, 6371-6376. [CrossRef]

23. Mortensen, M.W.; Björkdahl, O.; Sørensen, P.G.; Hansen, T.; Jensen, M.R.; Gundersen, H.J.G.; Bjørnholm, T. Functionalization and cellular uptake of boron carbide naraoparticles. The first step toward T cell-guided boron neutron capture therapy. Bioconjugate Chem. 2006, 17, 284-290. [CrossRef] [PubMed]

24. Mortensen, M.W.; Sørensen, P.G.; Björkdahl, O.; Jensen, M.R.; Gundersen, H.J.G.; Bjørnholm, T. Preparation and characterization of Boron carbide nanoparticles for use as a novel agent in T cell-guided boron neutron capture therapy. Appl. Radiat. Isot. 2006, 64, 315-324. [CrossRef]

25. Grandi, S.; Spinella, A.; Tomasi, C.; Bruni, G.; Fagnoni, M.; Merli, D.; Mustarelli, P.; Guidetti, G.F.; Achilli, C.; Balduini, C. Synthesis and characterisation of functionalized borosilicate nanoparticles for boron neutron capture therapy applications. J. Sol-Gel Sci. Technol. 2012, 64, 358-366. [CrossRef]

26. Vigderman, L.; Zubarev, E.R. Therapeutic platforms based on gold nanoparticles and their covalent conjugates with drug molecules. Adv. Drug Del. Rev. 2013, 65, 663-676. [CrossRef] [PubMed]

27. Mahato, K.; Nagpal, S.; Shah, M.A.; Srivastava, A.; Maurya, P.K.; Roy, S.; Jaiswal, A.; Singh, R.; Chandra, P. Gold nanoparticle surface engineering strategies and their applications in biomedicine and diagnostics. 3 Biotech 2019, 9, 57. [CrossRef]

28. Panahi, Y.; Mohammadhosseini, M.; Nejati-Koshki, K.; Abadi, A.J.N.; Moafi, H.F.; Akbarzadeh, A.; Farshbaf, M. Preparation, Surface Properties, and Therapeutic Applications of Gold Nanoparticles in Biomedicine. Drug Res. 2017, 67, 77-87. [CrossRef]

29. Versiani, A.F.; Andrade, L.M.; Martins, E.M.N.; Scalzo, S.; Geraldo, J.M.; Chaves, C.R.; Ferreira, D.C.; Ladeira, M.; Guatimosim, S.; Ladeira, L.O.; et al. Gold nanoparticles and their applications in biomedicine. Future Virol. 2016, 11, 293-309. [CrossRef] 
30. Schmid, G.; Pugin, R.; Meyer-Zaika, A.W.; Simon, U. Clusters on clusters: closo-dodecaborate as a ligand for $\mathrm{Au}_{55}$ clusters. Eur. J. Inorg. Chem. 1999, 2051-2055. [CrossRef]

31. Liang, L.; Rapakousiou, A.; Salmon, L.; Ruiz, J.; Astruc, D.; Dash, B.P.; Satapathy, R.; Sawicki, J.W.; Hosmane, N.S. "Click" assembly of carborane-appended polymers and stabilization of gold and palladium nanoparticles. Eur. J. Inorg. Chem. 2011, 3043-3049. [CrossRef]

32. Cioran, A.M.; Teixidor, F.; Krpetić, Ž.; Brust, M.; Viñas, C. Preparation and characterization of Au nanoparticles capped with mercaptocarboranyl clusters. Dalton Trans. 2014, 43, 5054-5061. [CrossRef] [PubMed]

33. Cioran, A.M.; Musteti, A.D.; Teixidor, F.; Krpetić, Z.; Prior, I.A.; He, Q.; Kiely, C.J.; Brust, M.; Viñas, C. Mercaptocarborane-capped gold nanoparticles: Electron pools and ion traps with switchable hydrophilicity. J. Am. Chem. Soc. 2012, 134, 212-221. [CrossRef] [PubMed]

34. Ciani, L.; Bortolussi, S.; Postuma, I.; Cansolino, L.; Ferrari, C.; Panza, L.; Altieri, S.; Ristori, S. Rational design of gold nanoparticles functionalized with carboranes for application in Boron Neutron Capture Therapy. Int. J. Pharm. 2013, 458, 340-346. [CrossRef] [PubMed]

35. Li, N.; Zhao, P.; Salmon, L.; Ruiz, J.; Zabawa, M.; Hosmane, N.S.; Astruc, D. “Click” star-shaped and dendritic PEGylated gold nanoparticle-carborane assemblies. Inorg. Chem. 2013, 52, 11146-11155. [CrossRef]

36. Wu, C.-Y.; Lin, J.-J.; Chang, W.-Y.; Hsieh, C.-Y.; Wu, C.-C.; Chen, H.-S.; Hsu, H.-J.; Yang, A.-S.; Hsu, M.-H.; Kuo, W.-Y. Development of theranostic active-targeting boron-containing gold nanoparticles for boron neutron capture therapy (BNCT). Colloids Surf. B Biointerfaces 2019, 183, 110387. [CrossRef]

37. Wang, J.; Chen, L.; Ye, J.; Li, Z.; Jiang, H.; Yan, H.; Stogniy, M.Y.; Sivaev, I.B.; Bregadze, V.I.; Wang, X. Carborane Derivative Conjugated with Gold Nanoclusters for Targeted Cancer Cell Imaging. Biomacromolecules 2017, 18, 1466-1472. [CrossRef]

38. Dash, B.P.; Satapathy, R.; Swain, B.R.; Mahanta, C.S.; Jena, B.B.; Hosmane, N.S. Cobalt bis(dicarbollide) anion and its derivatives. J. Organomet. Chem. 2017, 849-850, 170-194. [CrossRef]

39. Sivaev, I.B.; Bregadze, V.I. Chemistry of cobalt bis(dicarbollides). A review. Collect. Czech. Chem. Commun. 1999, 64, 783-805. [CrossRef]

40. Llop, J.; Masalles, C.; Viñas, C.; Teixidor, F.; Sillanpää, R.; Kivekäs, R. The $\left[3,3^{\prime}-\mathrm{Co}\left(1,2-\mathrm{C}_{2} \mathrm{~B}_{9} \mathrm{H}_{11}\right)_{2}\right]$-anion as a platform for new materials: Synthesis of its functionalized monosubstituted derivatives incorporating synthons for conducting organic polymers. J. Chem. Soc. Dalton Trans. 2003, 556-561. [CrossRef]

41. Gabel, D.; Foster, S.; Fairchild, R.G. The Monte Carlo simulation of the biological effect of the ${ }^{10} \mathrm{~B}(\mathrm{n}, \alpha){ }^{7} \mathrm{Li}$ reaction in cells and tissue and its implication for boron neutron capture therapy. Radiat. Res. 1987, 111, 14-25. [CrossRef] [PubMed]

42. Fairchild, R.G.; Bond, V.P. Current status of ${ }^{10}$ B-neutron capture therapy: Enhancement of tumor dose via beam filtration and dose rate, and the effects of these parameters on minimum boron content: A theoretical evaluation. Int. J. Radiat. Oncol. Biol. Phys. 1985, 11, 831-840. [CrossRef]

43. Stylianopoulos, T. EPR-effect: Utilizing size-dependent nanoparticle delivery to solid tumors. Ther. Deliv. 2013, 4, 421-423. [CrossRef] [PubMed]

44. Schulz, F.; Homolka, T.; Bastús, N.G.; Puntes, V.; Weller, H.; Vossmeyer, T. Little adjustments significantly improve the Turkevich synthesis of gold nanoparticles. Langmuir 2014, 30, 10779-10784. [CrossRef]

45. Wagner, C.D.; Naumkin, A.V.; Kraut-Vass, A.; Allison, J.W.; Powell, C.J.; Rumble, J.R.J. NIST X-ray Photoelectron Spectroscopy Database National Institute of Standards and Technology. Available online: https://srdata.nist.giv/xps/ (accessed on 25 May 2019).

46. Di Mauro, P.P.; Gómez-Vallejo, V.; Baz Maldonado, Z.; Llop Roig, J.; Borrós, S. Novel 18F Labeling Strategy for Polyester-Based NPs for In Vivo PET-CT Imaging. Bioconjugate Chem. 2015, 26, 582-592. [CrossRef]

47. Royo, F.; Cossío, U.; Ruiz De Angulo, A.; Llop, J.; Falcon-Perez, J.M. Modification of the glycosylation of extracellular vesicles alters their biodistribution in mice. Nanoscale 2019, 11, 1531-1537. [CrossRef]

48. Frigell, J.; García, I.; Gómez-Vallejo, V.; Llop, J.; Penadés, S. 68Ga-labeled gold glyconanoparticles for exploring blood-brain barrier permeability: Preparation, biodistribution studies, and improved brain uptake via neuropeptide conjugation. J. Am. Chem. Soc. 2014, 136, 449-457. [CrossRef]

49. Llop, J.; Gómez-Vallejo, V.; Gibson, N. Quantitative determination of the biodistribution of nanoparticles: Could radiolabeling be the answer? Nanomedicine 2013, 8, 1035-1038. [CrossRef] 
50. Pérez-Campaña, C.; Gómez-Vallejo, V.; Puigivila, M.; Martín, A.; Calvo-Fernández, T.; Moya, S.E.; Ziolo, R.F.; Reese, T.; Llop, J. Biodistribution of different sized nanoparticles assessed by positron emission tomography: A general strategy for direct activation of metal oxide particles. ACS Nano 2013, 7, 3498-3505. [CrossRef] [PubMed]

51. Polyak, A.; Ross, T.L. Nanoparticles for SPECT and PET imaging: Towards personalized medicine and theranostics. Curr. Med. Chem. 2018, 25, 4328-4353. [CrossRef] [PubMed]

52. Varani, M.; Galli, F.; Auletta, S.; Signore, A. Radiolabelled nanoparticles for cancer diagnosis. Clin. Transl. Imaging 2018, 6, 271-292. [CrossRef]

53. Llop, J.; Jiang, P.; Marradi, M.; Gómez-Vallejo, V.; Echeverría, M.; Yu, S.; Puigivila, M.; Baz, Z.; Szczupak, B.; Pérez-Campaña, C.; et al. Visualisation of dual radiolabelled poly(lactide-co-glycolide) nanoparticle degradation In Vivo using energy-discriminant SPECT. J. Mater. Chem. B 2015, 3, 6293-6300. [CrossRef]

54. Gona, K.B.; Zaulet, A.; Gómez-Vallejo, V.; Teixidor, F.; Llop, J.; Viñas, C. COSAN as a molecular imaging platform: Synthesis and "In Vivo" imaging. Chem. Commun. 2014, 50, 11415-11417. [CrossRef] [PubMed]

55. Shao, X.; Zhang, H.; Rajian, J.R.; Chamberland, D.L.; Sherman, P.S.; Quesada, C.A.; Koch, A.E.; Kotov, N.A.; Wang, X. 125I-labeled gold nanorods for targeted imaging of inflammation. ACS Nano 2011, 5, 8967-8973. [CrossRef]

56. Agarwal, A.; Shao, X.; Rajian, J.R.; Zhang, H.; Chamberland, D.L.; Kotov, N.A.; Wang, X. Dual-mode imaging with radiolabeled gold nanorods. J. Biomed. Opt. 2011, 16, 051307. [CrossRef] [PubMed]

57. Suzuki, M. Boron neutron capture therapy (BNCT): a unique role in radiotherapy with a view to entering the accelerator-based BNCT era. Int. J. Clin. Oncol. 2019, 1-8. [CrossRef]

58. Kaushal, A.; Citrin, D. The Role of Radiation Therapy in the Management of Sarcomas. Surg. Clin. N. Am. 2008, 88, 629-646. [CrossRef]

59. Zhou, X.Y.; Dorn, M.; Vogt, J.; Spemann, D.; Yu, W.; Mao, Z.W.; Estrela-Lopis, I.; Donath, E.; Gao, C.Y. A quantitative study of the intracellular concentration of graphene/noble metal nanoparticle composites and their cytotoxicity. Nanoscale 2014, 6, 8535-8542. [CrossRef]

60. Veith, L.; Bottner, J.; Vennemann, A.; Breitenstein, D.; Engelhard, C.; Meijer, J.; Estrela-Lopis, I.; Wiemann, M.; Hagenhoff, B. Detection of $\mathrm{ZrO}(2)$ Nanoparticles in Lung Tissue Sections by Time-of-Flight Secondary Ion Mass Spectrometry and Ion Beam Microscopy. Nanomaterials 2018, 8. [CrossRef]

61. Meyer, T.; Venus, T.; Sieg, H.; Bohmert, L.; Kunz, B.M.; Krause, B.; Jalili, P.; Hogeveen, K.; Chevance, S.; Gauffre, F.; et al. Simultaneous Quantification and Visualization of Titanium Dioxide Nanomaterial Uptake at the Single Cell Level in an In Vitro Model of the Human Small Intestine. Small Methods 2019, 3, 18500540. [CrossRef]

62. Lichtenstein, D.; Meyer, T.; Bohmert, L.; Juling, S.; Fahrenson, C.; Selve, S.; Thunemann, A.; Meijer, J.; Estrela-Lopis, I.; Braeuning, A.; et al. Dosimetric Quantification of Coating-Related Uptake of Silver Nanoparticles. Langmuir 2017, 33, 13087-13097. [CrossRef] [PubMed]

63. Estrela-Lopis, I.; Romero, G.; Rojas, E.; Moya, S.E.; Donath, E. Nanoparticle uptake and their co-localization with cell compartments-A confocal Raman microscopy study at single cell level. J. Phys. CS 2011, 304, 1-10. [CrossRef]

64. Romero, G.; Estrela-Lopis, I.; Castro-Hartmann, P.; Rojas, E.; Llarena, I.; Sanz, D.; Donath, E.; Moya, S.E. Stepwise surface tailoring of carbon nanotubes with polyelectrolyte brushes and lipid layers to control their intracellular distribution and "in vitro" toxicity. Soft Matt. 2011, 7, 6883-6890. [CrossRef]

65. Romero, G.; Estrela-Lopis, I.; Zhou, J.; Rojas, E.; Franco, A.; Espinel, C.S.; Fernandez, A.G.; Gao, C.Y.; Donath, E.; Moya, S.E. Surface Engineered Poly(lactide-co-glycolide) Nanoparticles for Intracellular Delivery: Uptake and Cytotoxicity-A Confocal Raman Microscopic Study. Biomacromolecules 2010, 11, 2993-2999. [CrossRef] [PubMed]

66. Llop, J.; Estrela-Lopis, I.; Ziolo, R.F.; Gonzalez, A.; Fleddermann, J.; Dorn, M.; Vallejo, V.G.; Simon-Vazquez, R.; Donath, E.; Mao, Z.G.; et al. Uptake, Biological Fate, and Toxicity of Metal Oxide Nanoparticles. Part. Part. Syst. Charact. 2014, 31, 24-35. [CrossRef]

67. Blucher, C.; Zilberfain, C.; Venus, T.; Spindler, N.; Dietrich, A.; Burkhardt, R.; Stadler, S.C.; Estrela-Lopis, I. Single cell study of adipose tissue mediated lipid droplet formation and biochemical alterations in breast cancer cells. Analyst 2019, 144, 5558-5570. [CrossRef] [PubMed] 
68. Coelho, J.M.; Camargo, N.S.; Ganassin, R.; Rocha, M.C.O.; Merker, C.; Böttner, J.; Estrela-Lopis, I.; Py-Daniel, K.R.; Jardim, K.V.; Sousa, M.H.; et al. Oily core/amphiphilic polymer shell nanocapsules change the intracellular fate of doxorubicin in breast cancer cells. J. Mater. Chem. B 2019. [CrossRef]

69. Ganassin, R.; Merker, C.; Rodrigues, M.C.; Guimaraes, N.F.; Sodre, C.S.C.; Ferreira, Q.D.S.; da Silva, S.W.; Ombredane, A.S.; Joanitti, G.A.; Py-Daniel, K.R.; et al. Nanocapsules for the co-delivery of selol and doxorubicin to breast adenocarcinoma $4 \mathrm{~T} 1$ cells in vitro. Artif. Cells Nanomed. Biotechnol. 2018, 46, 2002-2012. [CrossRef]

70. Arnida; Janát-Amsbury, M.M.; Ray, A.; Peterson, C.M.; Ghandehari, H. Geometry and surface characteristics of gold nanoparticles influence their biodistribution and uptake by macrophages. Eur. J. Pharm. Biopharm. 2011, 77, 417-423. [CrossRef] [PubMed]

71. Duncan, R.; Sat-Klopsch, Y.N.; Burger, A.M.; Bibby, M.C.; Fiebig, H.H.; Sausville, E.A. Validation of tumour models for use in anticancer nanomedicine evaluation: The EPR effect and cathepsin B-mediated drug release rate. Cancer Chemother. Pharmacol. 2013, 72, 417-427. [CrossRef] [PubMed]

72. Yanagie, H.; Maruyama, K.; Takizawa, T.; Ishida, O.; Ogura, K.; Matsumoto, T.; Sakurai, Y.; Kobayashi, T.; Shinohara, A.; Rant, J.; et al. Application of boron-entrapped stealth liposomes to inhibition of growth of tumour cells in the In Vivo boron neutron-capture therapy model. Biomed. Pharmacother. 2006, 60, 43-50. [CrossRef] [PubMed]

73. Koganei, H.; Ueno, M.; Tachikawa, S.; Tasaki, L.; Ban, H.S.; Suzuki, M.; Shiraishi, K.; Kawano, K.; Yokoyama, M.; Maitani, Y.; et al. Development of high boron content liposomes and their promising antitumor effect for neutron capture therapy of cancers. Bioconjugate Chem. 2013, 24, 124-132. [CrossRef] [PubMed]

74. Yinghuai, Z.; Peng, A.T.; Carpenter, K.; Maguire, J.A.; Hosmane, N.S.; Takagaki, M. Substituted carborane-appended water-soluble single-wall carbon nanotubes: New approach to boron neutron capture therapy drug delivery. J. Am. Chem. Soc. 2005, 127, 9875-9880. [CrossRef] [PubMed]

75. Zhu, Y.; Lin, Y.; Zhu, Y.Z.; Lu, J.; Maguire, J.A.; Hosmane, N.S. Boron drug delivery via encapsulated magnetic nanocomposites: A new approach for BNCT in cancer treatment. J. Nanomater. 2010, 2010. [CrossRef]

76. Gao, S.; Zhu, Y.; Hosmane, N. Nanostructured Boron Compounds for Boron Neutron Capture Therapy (BNCT) in Cancer Treatment. In Boron-Based Compounds: Potential and Emerging Applications in Medicine; Hey-Hawkins, E., Viñas, C., Eds.; John Wiley \& Sons Ltd.: Hoboken, NJ, USA, 2018; pp. 371-388.

77. Mulware, S.J.; Baxley, J.D.; Rout, B.; Reinert, T. Efficiency calibration of an HPGe X-ray detector for quantitative PIXE analysis. Nucl. Instr. Methods Phys. Res. Sect. B-Beam Interact. Mater. Atoms 2014, 332, 95-98. [CrossRef]

Sample Availability: Samples of the compounds are not available from the authors.

(C) 2019 by the authors. Licensee MDPI, Basel, Switzerland. This article is an open access article distributed under the terms and conditions of the Creative Commons Attribution (CC BY) license (http://creativecommons.org/licenses/by/4.0/). 